\title{
Salting-in with a Salting-out Agent: Explaining the Cation Specific Effects on the Aqueous Solubility of Amino Acids
}

\author{
Luciana I. N. Tomé, ${ }^{\dagger}$ Simão P. Pinho, ${ }^{\ddagger}$ Miguel Jorge, ${ }^{\S, \|}$ José R. B. Gomes, ${ }^{\dagger}$ and João A. P. Coutinho* ${ }^{\dagger}$ \\ ${ }^{\dagger}$ CICECO, Departamento de Química, Universidade de Aveiro, Campus Universitário de Santiago, 3810-193 Aveiro, Portugal \\ ${ }^{\ddagger}$ LSRE - Laboratory of Separation and Reaction Engineering - Associate Laboratory LSRE/LCM, Instituto Politécnico de Bragança, \\ Campus de Santa Apolónia, 5301-85 Bragança, Portugal \\ ${ }^{\S}$ LSRE - Laboratory of Separation and Reaction Engineering - Associate Laboratory LSRE/LCM, Faculdade de Engenharia da \\ Universidade do Porto, Rua Dr. Roberto Frias, 4200-465 Porto, Portugal \\ "Department of Chemical and Process Engineering, University of Strathclyde, 75 Montrose Street, Glasgow G1 1XJ, United Kingdom
}

Supporting Information

ABSTRACT: Although the understanding of ion specific effects on the aqueous solubilities of biomolecules is crucial for the development of many areas of biochemistry and life sciences, a consensual and well-supported molecular picture of the phenomena has not yet been established. Mostly, the influence of cations and the nature of the molecular interactions responsible for the reversal of the Hofmeister trend in aqueous solutions of amino acids and proteins are still defectively understood. Aiming at contributing to the understanding of the molecular-level mechanisms governing the cation specific effects on the aqueous solubilities of biocompounds, experimental solubility measurements and classical molecular dynamics simulations were performed for aqueous solutions of three amino acids (alanine, valine, and isoleucine), in the presence of a series of inorganic salts. The evidence gathered suggests that the mechanism by which salting-in inducing cations operate in aqueous solutions of amino acids is different from that of anions, and allows for a novel and consistent molecular description of the effect of the cation on the solubility based on specific interactions of the cations with the negatively charged moieties of the biomolecules.

\section{INTRODUCTION}

The solubility behavior of biomolecules in aqueous electrolyte solutions assumes a very important role in the life sciences and biotechnological developments. In spite of the large amount of work dedicated to this subject throughout the years, the molecular level description of the effects of the nature and concentration of ions in biological media is still not consensual and definitely established. The lack of a deep and wellsupported molecular picture of the interactions which govern the biochemistry of vital processes is still one of the major critical issues in biochemistry and is actually limiting the development of medical and pharmaceutical solutions for diseases induced by biochemical disorders ${ }^{1-3}$ and the improvement of the efficiency of biotechnological processes. ${ }^{4,5}$

While the rank of the relative influence of ions on the physicochemical behavior of aqueous systems, known as the Hofmeister series, ${ }^{6}$ is well established and consensually recognized as general in a wide range of processes, ${ }^{7-10}$ several, sometimes contradictory, molecular level interpretations of the phenomena have been proposed during the past century. $7,9,11-24$ Lately, spearheaded by its biological, medical, and biotechnological relevance, there has been a renewed interest in this area. As new data become available, ${ }^{25-30}$ long- held classical ideas about changes in bulk water structure ${ }^{11-14}$ are progressively being overturned, and newer theories, emphasizing the significant role of dispersion forces, ionic polarizabilities and the specific ion binding, have been proposed. ${ }^{15,16,31,32}$ One of the most consistent theories was suggested by Zhang and co-workers ${ }^{9,17,18}$ who described ion specific effects on the solubilities of macromolecules in terms of direct interactions of the ions with the solutes and with water molecules. This theory formed in fact a basis for the model that we have been developing and refining to interpret the solubility of charged molecules in aqueous solutions of inorganic salts or amino acids ${ }^{19-22,24}$ and to explain the behavior of aqueous saline solutions of amino acids, ${ }^{23}$ which is consistent with the most recent theories that underline the central role of ionic polarizabilities and of ion size in the interpretation of Hofmeister effects. ${ }^{31,32}$ Despite a century of efforts, however, in an era characterized by profound technological and scientific advances, the knowledge of the molecular level interactions which govern the behavior of biomolecules in aqueous saline

Received: March 1, 2013

Revised: April 4, 2013

Published: May 2, 2013 
environments is still elusive. Therefore, further investigation on this subject, using alternative approaches and methods capable of providing reliable evidence, is required.

As the simplest building blocks of more complex biomolecules, amino acids are ideal molecules to be studied as model compounds. The effect of ions on amino acid aqueous solubilities follows the Hofmeister series and is experimentally well documented and phenomenologically well established. Experimental measurements of the solubility of amino acids in (water+salt) mixtures ${ }^{33-42}$ reveal that this property is affected by the nature and concentration of both the cation and the anion of the electrolyte, as well as by the structural characteristics of the biomolecules, $\mathrm{pH}$, and temperature. In previous studies, ${ }^{23}$ molecular dynamics (MD) simulation data were used by us in an attempt to interpret, at a molecular level, the experimentally observed solubility behavior of amino acids in aqueous saline solutions. The influence of the nature of the anion and of the amino acids, and the effect of salt concentration were considered, but there are still some questions concerning the molecular mechanism that remain unanswered and need to be clarified. Particularly, the specific effects of cations have been difficult to explain. Actually, although a few works provide some clues about the mechanisms responsible for the unexpected reversal of the Hofmeister trend observed for cations in aqueous solutions of proteins, ${ }^{42-45}$ the exact nature of the molecular interactions is still defectively understood. In particular, a well supported molecular picture of the ion-specific nature of the interactions between sites of negative charge on proteins and cations has not yet been provided. ${ }^{45}$ In order to further contribute to the understanding of the molecular mechanisms occurring in these systems, thermodynamic and MD simulation methods are used here to study the interactions between amino acids and salts in aqueous media and to evaluate their dependence on the physicochemical characteristics of the cation. With that aim, experimental solubility measurements and MD simulations were performed for aqueous solutions of three amino acids, alanine (Ala), valine (Val), and isoleucine (Ile), all depicted in Figure 1, in the presence of salts such as $\mathrm{MgCl}_{2}, \mathrm{MgSO}_{4}$,

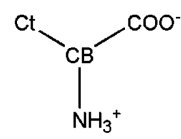

(i)

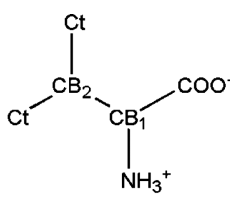

(ii)

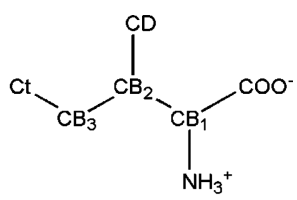

(iii)
Figure 1. Structure and atom labeling of the amino acids studied in this work: (i) alanine (Ala), (ii) valine (Val), and (iii) isoleucine (Ile).

$\mathrm{NH}_{4} \mathrm{Cl}$, and $\left(\mathrm{NH}_{4}\right)_{2} \mathrm{SO}_{4}$, at $\mathrm{T}=298.15 \mathrm{~K}$. The ions were selected in order to assess the effect of the nature and charge of the cation on the amino acids aqueous solubilities. Moreover, because natural environments are very often neutral, the solubility measurements were carried out in a $\mathrm{pH}$ range close to the isoelectric point and therefore only the zwitterionic forms of the solutes were considered in the simulations.

MD simulation methods have proved to be a valuable tool for the investigation of biochemical systems, including aqueous solutions and aqueous saline solutions of amino acids, peptides, proteins, lipid bilayers, and hydrophobic solutes, ${ }^{32,46-56}$ and we have previously used them with success to characterize the interactions behind the influence of salts on the behavior of amino acids and of other charged molecules such as ionic liquids (IL) in aqueous mixtures. ${ }^{22-24}$ Despite the existence of a large amount of work focusing on the solubility and stability of amino acids and proteins in the presence of salts, ${ }^{31,33-43,47,57,58}$ the experimental solubility data available for the systems envisaged in the current study are very scarce, ${ }^{40}$ not to mention the paucity of theoretical investigations. In this work, the analysis of the radial distribution functions (RDFs) of the various groups and moieties, estimated by MD, will provide an explanation for the solubility behavior experimentally observed for the aqueous solutions of amino acids and salts considered here.

\section{EXPERIMENTAL SECTION}

2.1. Chemicals. Ammonium sulfate and ammonium chloride $99.5 \%$ minimum purity were supplied by Merck, while magnesium chloride hexahydrate and magnesium sulfate heptahydrate both supplied by Panreac were 99\% minimum purity. The amino acids DL-alanine and L-valine (Merck) and Lisoleucine (Fluka) were 99\% minimum purity. All chemicals were used as received, and excluding the hydrated salts the solids were kept in a dehydrator with silica gel to avoid water contamination. In all experiments, double-ionized water was used.

2.2. Experimental Procedure. The solubility experiments were carried out using the analytical isothermal shake-flask method. Saturated solutions were prepared by mixing a small excess of solid solute with about $80 \mathrm{~cm}^{3}$ of solvent, already prepared by weighing $( \pm 0.1 \mathrm{mg})$ the appropriated amounts of salt and water. To reach equilibrium, the solution was continuously stirred for $48 \mathrm{~h}$ and later the solution was allowed to settle at least $12 \mathrm{~h}$ before sampling. In this process, temperature was monitored with four-wire platinum resistance probes (Pt-104, Pico-Technology) placed in direct contact with the solutions. This temperature measuring system was previously calibrated, ensuring that the solution temperature is within $\pm 0.1 \mathrm{~K}$ of the set temperature.

Samples $\left(5 \mathrm{~cm}^{3}\right)$ of the saturated liquid phase were subsequently collected using plastic syringes coupled with previously heated polypropylene filters $(0.45 \mu \mathrm{m})$ in order to avoid precipitation. Depending on the salt, two different methods were chosen for quantitative analysis. The gravimetric method was selected for the nonhydrated salts. Therefore, the samples were placed into preweighed glass vessels and immediately weighed. Then, all the solvent was evaporated, and the crystals dried completely in a drying stove at $343.15 \mathrm{~K}$ for 3 days. Finally, the glass vessels were cooled in a dehydrator with silica gel for 1 day and weighed. The process was regularly repeated until a constant mass value was achieved. Each solubility value was an average of at least three different measurements.

For the solutions of hydrated salts, density measurements were performed instead, using a vibrating tube digital density meter (DMA $5000 \mathrm{M}$, Anton Paar) with a reproducibility within $\pm 3 \times 10^{-3} \mathrm{~kg} / \mathrm{m}^{3}$. In this way, the samples were discharged into glass vessels containing a known weighed amount (between 12 and $15 \mathrm{~g}$ ) of binary salt aqueous solution at the same salt molality as the ternary saturated solution. After mixing, densities were measured following standard procedures. For each solubility value, four independent density measurements were performed, which were converted into solubility after consideration of a linear calibration curve $\left(r^{2}>0.999\right)$ relating the amino acid concentration (in $\mathrm{g} / \mathrm{kg}$ of water) and 
the density. The accuracy of the implemented methodology was checked by measuring the densities of some ternary solutions of known concentration of amino acids. The maximum difference found between the real and calculated concentration was $0.6 \mathrm{~g}$ of amino acid per $\mathrm{kg}$ of water.

The $\mathrm{pH}$ was also measured (inoLab $\mathrm{pH} 720$, WTW) at 298.15 K for some saturated amino acid solutions at the highest salt molality, showing a minor effect on solubility change as it varies from $\mathrm{pH}=4.81$ in a saturated solution of isoleucine (in $\mathrm{MgCl}_{2}$ ) to $\mathrm{pH}=5.90$ in a saturated alanine aqueous $2 \mathrm{~m}$ $\mathrm{NH}_{4} \mathrm{Cl}$ solution.

2.3. Computational Methods. MD calculations were performed for aqueous solutions of the zwitterionic forms of the amino acids $(\mathrm{pH}=7)$ at a concentration of approximately $0.35 \mathrm{~mol} \mathrm{dm}^{-3}$ in the presence of the salts. A concentration of $1.0 \mathrm{~mol} \mathrm{dm}{ }^{-3}$ was selected for the salts. The simulations were carried out using the isothermal-isobaric NpT $(T=298.15 \mathrm{~K}$ and $p=1$ bar) ensemble and the GROMACS 4.04 molecular dynamics package. ${ }^{59}$ The equations of motion were integrated with the Verlet-Leapfrog algorithm ${ }^{60}$ and a time step of 2 fs. The Nosé-Hoover thermostat ${ }^{61,62}$ was used to fix the temperature, while the Parrinello-Rahman barostat ${ }^{63}$ was employed to fix the pressure. Starting configurations were generated in cubic boxes with lateral dimensions of $45 \AA$, and periodic boundary conditions were applied in three dimensions. The systems were prepared by randomly placing amino acids, ions and water molecules in the simulation box. Six amino acid molecules were included in each box, solvated by 900 water molecules, and 17 cation-anion pairs were incorporated to obtain the $1.0 \mathrm{M}$ salt concentration. Then, a 10000 step energy minimization was performed and followed by two simulations, the first one with 50000 steps for equilibration and the final one with 10000000 steps for production (i.e., total production time of $20 \mathrm{~ns}$ ). After equilibration, the values of the box volume ranged between 27.1 and $30.2 \mathrm{~nm}^{3}$, depending on the particular combination of amino acids and ions. Equilibration was checked by ensuring that all observables (including the $\mathrm{RDFs}$ ) fluctuated around their equilibrium values during the production stage.

The intermolecular interaction energy between pairs of neighboring atoms was calculated using the Lennard-Jones potential to describe dispersion/repulsion forces and the pointcharge Coulomb potential for electrostatic interactions. Longrange electrostatic interactions were accounted for using the particle-mesh Ewald method, ${ }^{64}$ with a cutoff of $1.0 \mathrm{~nm}$ for the real-space part of the interactions. A cutoff radius of $1.2 \mathrm{~nm}$ was used for the Lennard-Jones potential, and long-range dispersion corrections were added to both energy and pressure. All bond lengths were held rigid using the LINCS constraint algorithm, ${ }^{65}$ while angle bending was modeled by a harmonic potential and dihedral torsion was described (where appropriate) by a Ryckaert-Bellemans function. Potentials available in the literature were taken for all the species considered in the simulations. Water was described by the rigid SPC/E model, ${ }^{66}$ while the OPLS all-atom potential was used for the amino acids ${ }^{67}$ and for the magnesium, ${ }^{67}$ chloride, ${ }^{68}$ and ammonium ${ }^{69}$ ions. For sulfate, the force field parameters of the second (std2) model proposed by Cannon et al. $^{70}$ were used.

One of the most critical issues when performing $\mathrm{MD}$ simulations is the choice of the force field, since it often has repercussions on the accuracy of the results obtained. ${ }^{52,71-73}$ For instance, small changes in the effective pair potential between interacting ions can significantly affect solution thermodynamics and contact ion-pairing, and thus some force fields have failed to reproduce realistically some properties of aqueous ionic solutions. ${ }^{74,75}$ The force fields selected for the ions in this work have provided accurate descriptions of aqueous saline solutions of amino acids, ${ }^{23}$ and it has been shown that, although absolute degrees of binding are somehow affected by the choice of the model, relative changes along the Hofmeister series are unchanged. ${ }^{23}$

Radial distribution functions for several atomic pairs were sampled during the production stage using the g_rdf tool of GROMACS. Coordination numbers $(\mathrm{CN})$ were calculated for the interactions between selected atoms. For that purpose, the function $N(r)$ was obtained by integrating the corresponding RDFs $(g(r))$ :

$$
N(r)=4 \pi \rho_{\mathrm{B}} \int_{0}^{r}\left(r^{2} g(r)\right) \mathrm{d} r
$$

where $\rho_{\mathrm{B}}$ is the number density of each atom in the bulk.

\section{RESULTS AND DISCUSSION}

3.1. Experimental. The measured values for the solubilities of the amino acids in the aqueous solutions of the different salts, at various electrolyte concentrations and at $T=298.15 \mathrm{~K}$, are presented in Tables 1-4, together with the standard

Table 1. Amino Acid Solubility ( $\mathrm{g} / \mathrm{kg}$ of water) at $T=298.15$ $\mathrm{K}$ and Different $\mathrm{NH}_{4} \mathrm{Cl}$ Molalities

$\begin{array}{cccc}\mathrm{NH}_{4} \mathrm{Cl} \text { molality } & \text { DL-alanine } & \text { L-isoleucine } & \text { L-valine } \\ 0.00 & 165.44(0.20) & 34.756(0.048) & 58.449(0.236) \\ 0.25 & - & 36.419(0.077) & - \\ 0.50 & 169.90(0.11) & 36.722(0.083) & 60.910(0.078) \\ 1.00 & 172.04(0.05) & 36.554(0.250) & 61.010(0.237) \\ 2.00 & 175.88(0.07) & 35.764(0.232) & 60.608(0.445)\end{array}$

Table 2. Amino Acid Solubility ( $\mathrm{g} / \mathrm{kg}$ of water) at $T=298.15$ $\mathrm{K}$ and Different $\left(\mathrm{NH}_{4}\right)_{2} \mathrm{SO}_{4}$ Molalities

\begin{tabular}{cccc}
$\begin{array}{c}\left(\mathrm{NH}_{4}\right)_{2} \mathrm{SO}_{4} \\
\text { molality }\end{array}$ & DL-alanine & \multicolumn{1}{c}{ L-isoleucine } & \multicolumn{1}{c}{ L-valine } \\
& $165.44(0.20)^{a}$ & $34.756(0.048)^{a}$ & $58.449(0.236)^{a}$ \\
0.00 & $165.77^{b}$ & $33.59^{b}$ & - \\
0.17 & $170.50^{b}$ & $34.15^{b}$ & - \\
0.23 & $172.28^{b}$ & $33.76^{b}$ & $59.629(0.240)^{a}$ \\
0.25 & - & - & - \\
0.33 & $173.57^{b}$ & $33.15^{b}$ & $57.941(0.240)^{a}$ \\
0.50 & $173.99^{b}$ & $32.04^{b}$ & - \\
0.70 & $173.71^{b}$ & $30.28^{b}$ & $51.921(0.109)^{a}$ \\
1.00 & $172.95^{b}$ & $27.03^{b}$ & - \\
1.50 & $167.56^{b}$ & $22.51^{b}$ & $39.947(0.321)^{a}$ \\
2.00 & $160.74^{b}$ & $18.67^{b}$ & \\
${ }^{b}$ Reference $40^{a}$ This work. & & \\
\hline
\end{tabular}

Table 3. Amino Acid Solubility ( $\mathrm{g} / \mathrm{kg}$ of water) at $T=298.15$ $\mathrm{K}$ and Different $\mathrm{MgCl}_{2}$ Molalities

$\begin{array}{cccc}\mathrm{MgCl}_{2} \text { molality } & \text { DL-alanine } & \text { L-isoleucine } & \text { L-valine } \\ 0.00 & 165.44(0.20) & 34.756(0.048) & 58.449(0.236) \\ 0.50 & 188.35(0.05) & 40.247(0.245) & 66.983(0.158) \\ 1.00 & 207.08(0.14) & 44.652(0.021) & 72.230(0.279) \\ 2.00 & 245.95(0.10) & 46.182(0.236) & 75.686(0.230)\end{array}$


Table 4. Amino Acid Solubility (g/kg of water) at $T=298.15$ $\mathrm{K}$ and Different $\mathrm{MgSO}_{4}$ Molalities

\begin{tabular}{cccc}
$\mathrm{MgSO}_{4}$ molality & DL-alanine & L-isoleucine & L-valine \\
0.00 & $165.44(0.20)$ & $34.756(0.048)$ & $58.449(0.236)$ \\
0.50 & $184.82(0.15)$ & $36.284(0.128)$ & $61.067(0.050)$ \\
1.00 & $192.61(0.20)$ & & $64.447(0.370)$ \\
2.00 & $188.91(0.17)$ & & \\
\hline
\end{tabular}

deviation (in brackets). The maximum coefficient of variation is $0.80 \%$ for the ammonium solutions and $0.61 \%$ for the magnesium solutions. Figure 2 shows the relative solubility,
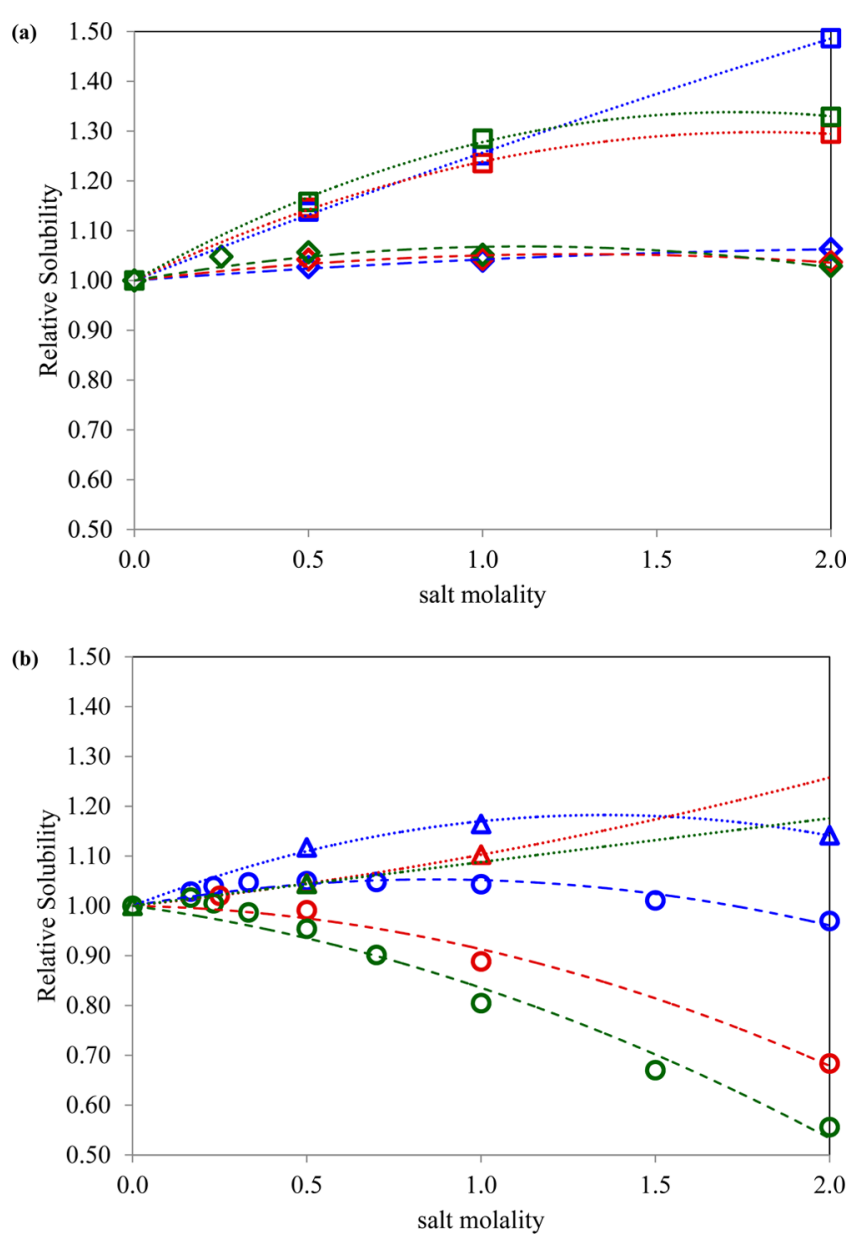

Figure 2. Relative solubility of alanine (blue), valine (red), and isoleucine (green) in (a) $\diamond, \mathrm{NH}_{4} \mathrm{Cl} ; \square, \mathrm{MgCl}_{2}$; and in (b) $\mathrm{O}$, $\left(\mathrm{NH}_{4}\right)_{2} \mathrm{SO}_{4} ; \triangle, \mathrm{MgSO}_{4}$ aqueous solutions, at $298.15 \mathrm{~K}$. Lines are guides to the eyes: dashed lines, $\mathrm{NH}_{4} \mathrm{Cl}$ and $\left(\mathrm{NH}_{4}\right)_{2} \mathrm{SO}_{4}$; dotted lines, $\mathrm{MgCl}_{2}$ and $\mathrm{MgSO}_{4}$. The values of the solubility of alanine and isoleucine in aqueous $\left(\mathrm{NH}_{4}\right)_{2} \mathrm{SO}_{4}$ solutions were taken from ref 40 .

expressed as the ratio between the solubility of the amino acid in the electrolyte solution to that in pure water, for the amino acids studied, in aqueous solutions of $\mathrm{NH}_{4} \mathrm{Cl}, \mathrm{MgCl}_{2}$, $\left(\mathrm{NH}_{4}\right)_{2} \mathrm{SO}_{4}$, and $\mathrm{MgSO}_{4}$.

Both increases (salting-in) and decreases (salting-out) of the amino acid aqueous solubilities are observed with the increase of the electrolyte concentration. As can be seen from Figure 2a, $\mathrm{NH}_{4} \mathrm{Cl}$ induces a salting-in effect on all the amino acids studied, with a magnitude dependent on the salt molality and on the nature of the biomolecule. For low $\mathrm{NH}_{4} \mathrm{Cl}$ concentrations $(\leq 1$ $m)$, the importance of this effect increases in the order Ala <
Val < Ile, while for higher molalities of the salt (e.g., $2 \mathrm{~m}$ ) the opposite trend is observed. The relative aqueous solubility of Ala shows an almost linear dependence on the electrolyte concentration; for $\mathrm{Val}$ and Ile, we observe an initial increase in the relative solubility until it reaches a maximum, followed by a decrease, which is more pronounced for Ile than for Val. As shown in Figure $2 \mathrm{~b},\left(\mathrm{NH}_{4}\right)_{2} \mathrm{SO}_{4}$ promotes salting-out of Val almost in the entire molality region (exception is the low molality regime), and this effect is more significant the higher the concentration of the salt.

The behavior of the magnesium salts is somewhat surprising. Given its extremely large energies of hydration, ${ }^{76,77}$ presented in Table $5, \mathrm{Mg}^{2+}$ should form hydration complexes ${ }^{78}$ that

Table 5. Molar Entropy of Hydration, $\Delta_{\text {hyd }} S$, and Gibbs Free Energy of Hydration, $\Delta_{\text {hyd }} G$, at 298.15 K for the Ions Studied in This Work ${ }^{76}$,

\begin{tabular}{lcc} 
ion & $\Delta_{\text {hyd }} \mathrm{S} /\left(\mathrm{J} \cdot \mathrm{K}^{-1} \cdot \mathrm{mol}^{-1}\right)$ & $\Delta_{\mathrm{hyd}} \mathrm{G} /\left(\mathrm{kJ} \cdot \mathrm{mol}^{-1}\right)$ \\
$\mathrm{Cl}^{-}$ & -75 & -340 \\
$\mathrm{SO}_{4}{ }^{2-}$ & -200 & -1080 \\
$\mathrm{NH}_{4}^{+}$ & & -285 \\
$\mathrm{Mg}^{2+}$ & -331 & -1830 \\
$\mathrm{Na}^{+}$ & -111 & -365 \\
$\mathrm{~K}^{+}$ & -74 & -295 \\
\hline
\end{tabular}

would contribute to a dehydration of the amino acids and their salting-out. This behavior is observed with other molecules such as ionic liquids ${ }^{79}$ and proteins. ${ }^{43,57}$ However, the solubility effects observed with the amino acids studied here are the opposite. The $\mathrm{Mg}^{2+}$ cation seems to be a strong salting-in agent, in good agreement with its "chaotropic" character described for other biomolecules such as polymers, ${ }^{80}$ charged polypeptides ${ }^{45}$ and some amino acids. ${ }^{43}$ In fact, $\mathrm{MgSO}_{4}$ and in particular $\mathrm{MgCl}_{2}$ have been found not only to have a rather unexpected behavior, but also to differ greatly from each other in their solubility effects on amino acids and proteins, and it has been inclusively suggested that the molecular-level mechanisms involving the interactions of these divalent cation salts with proteins are more complicated than those proposed for monovalent cations, such as $\mathrm{Na}^{+}$, and are still not consensual. $^{43,45}$ As shown in Figure $2 \mathrm{a}, \mathrm{MgCl}_{2}$ induces a pronounced salting-in of all the amino acids considered in this work, with a magnitude that increases with the molality of the salt. This increase is more significant and almost linear for Ala, while for $\mathrm{Val}$ and Ile it is smoother. $\mathrm{MgSO}_{4}$ (Figure $2 \mathrm{~b}$ ) also induces salting-in of all the amino acids, though less pronounced than that observed in aqueous solutions of magnesium chloride. For Ala, a significant initial increase in the relative solubility is followed by a decrease of the salting-in effect for higher salt concentrations. In the case of Ile, it was only possible to determine the solubility at $0.5 \mathrm{MgSO}_{4}$ molality, since experimental difficulties did not allow us to obtain the solubility of this amino acid at higher concentrations of this salt. The point obtained at $0.5 \mathrm{~mol} \mathrm{~kg}{ }^{-1}$ has, however, a high precision, and therefore it is possible to reliably state that magnesium sulfate induces salting-in of Ile at low concentrations.

Due to the scarcity of amino acid solubility data in aqueous electrolyte systems, no comparison is at the moment possible. However, the previous experience of the authors on these measurements, ${ }^{38-40}$ the low standard deviations observed and a careful analysis of the solubility of the amino acids in water, all 
support the quality of the measured data. In fact, the solubilities in pure water of the three amino acids considered in this work compare well with results available in the literature. The solubility of DL-alanine is in high agreement with the value given by Ferreira et al., ${ }^{38}$ and that of L-isoleucine is within the values presented in the detailed comparison published by Ferreira et al. ${ }^{39}$ (see Table 2). Concerning L-valine, the solubility measured in this work, that is, $58.45 \mathrm{~g} / \mathrm{kg}$ of water, is in very good agreement with the average solubility from five independent sources, ${ }^{81-83}$ which is $58.7 \mathrm{~g} / \mathrm{kg}$ of water, supporting the quality of the data measured in this work.

3.2. MD simulations. To understand the specific effects of ions on the aqueous solubilities of the amino acids in terms of their molecular-level interactions, MD simulations of Ala, Val, and Ile in water or in aqueous salt solutions were performed. Radial distribution functions (RDFs) were calculated for all the possible interactions involving the amino acid constituting groups (Figure 1), the anions, the cations, and water. These RDFs provide a quantitative description of enhancement (values larger than 1) or depletion (values smaller than 1) of densities of species around a selected moiety. The most relevant RDFs are presented in the main body of the paper, while additional plots are provided as Supporting Information.

Solute-Water Interactions. We start by analyzing the RDFs of water around the amino acid molecules, shown in Figure 3 for Ile (for which the effects are more evident) and in the Supporting Information for the other amino acids (Figures S1 and S2). The evidence obtained for the interaction pattern of the amino acids with water does not actually show significant differences in the hydration of the biomolecules among the different systems studied, but only minor dissimilarities which are likely to be related to a slight dehydration of the amino acids induced by the salts. As shown in Figure 3a, there are no significant differences in the water distribution around the terminal carbon atoms of the amino acids due to the presence of the salts. Instead, only small, yet noticeable, decreases of the intensities of the peaks when going from the ammonium to the magnesium salts are observed around the apolar moieties of the biomolecules, suggesting that these are slightly more hydrated in the presence of the $\mathrm{NH}_{4}^{+}$cation than in the presence of $\mathrm{Mg}^{2+}$. These results are in good agreement with the hydration properties of the cations ${ }^{76,77}$ reported in Table 5 and expected from the formation of hydration complexes that results from the strong hydration of magnesium ions in solution. ${ }^{78}$ On the other hand, the charged amino group is more hydrated in systems comprising the chloride salts (Figure $3 b$ ), while the interactions of $\mathrm{COO}^{-}$with water are decreased by the presence of all the electrolytes (Figure 3c). As discussed below, these differences in amino acid hydration are at least partly due to specific interactions between these molecules and the ions in solution.

The Role of the Anion. The patterns of interaction of the anions with the biomolecules are similar to those observed in a previous work ${ }^{23}$ dealing with the solubility of amino acids in aqueous solutions of sodium-based salts. Actually, the RDFs displayed in Figure 4 for Ile do not reveal the presence of the sulfate ion in the first solvation layer around the nonpolar moieties of the amino acids, but show a clear and intense binding to their positively charged groups. Although the interaction of $\mathrm{SO}_{4}^{2-}$ with the carboxylate group is also significant, this affinity is a consequence of the presence of the cations around $\mathrm{COO}^{-}$in the aqueous solutions, which shield unfavorable interactions of the anions with the negatively (a)

ISOLEUCINE: $\mathrm{C}_{\mathrm{t}}$ (amino acid)_O $\left(\mathrm{H}_{2} \mathrm{O}\right)$

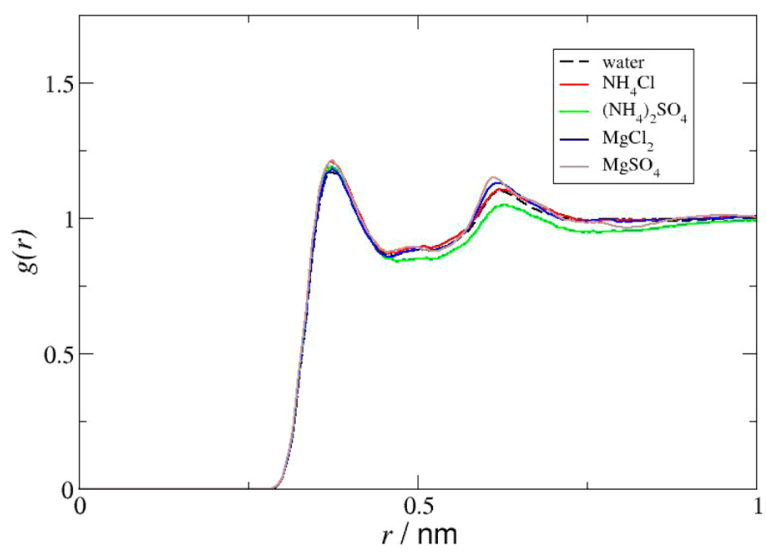

(b)

ISOLEUCINE: $\mathrm{H}\left(\mathrm{NH}_{3}{ }^{+}\right.$, amino acid)_O $\left(\mathrm{H}_{2} \mathrm{O}\right)$

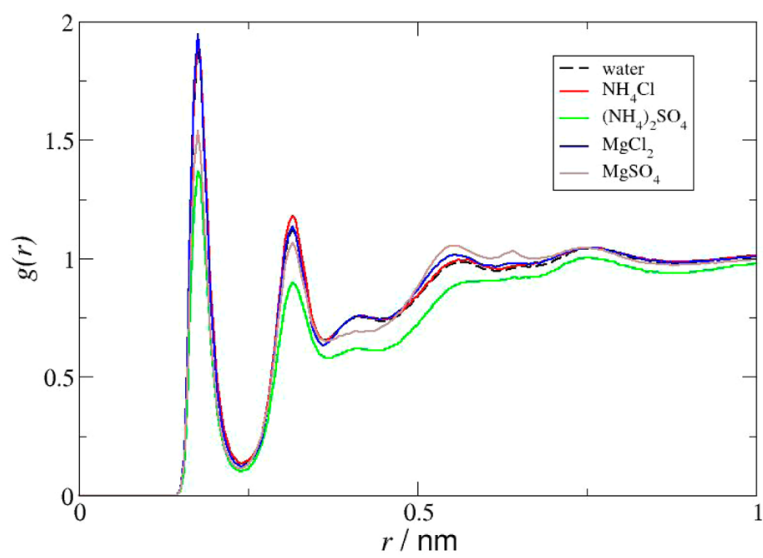

(c)

ISOLEUCINE: $\mathrm{O}\left(\mathrm{COO}^{-}\right.$, amino acid)_H $\left(\mathrm{H}_{2} \mathrm{O}\right)$

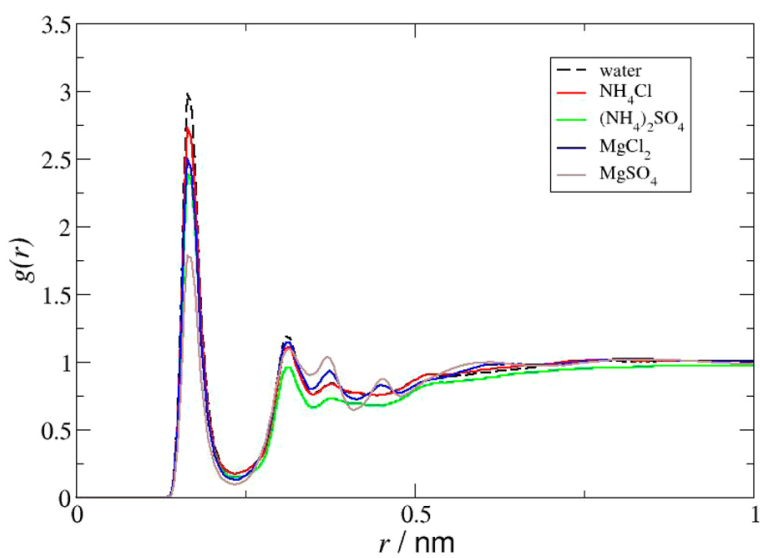

Figure 3. Radial distribution functions of the oxygen and hydrogen atoms of water around selected groups of isoleucine.

charged parts of the amino acids and promote the indirect binding observed in the RDFs. In fact, the strong peak observed for $\mathrm{MgSO}_{4}$ in Figure 4c, as well as the very strong first peak for this ion pair observed in Figure $9 \mathrm{~b}$, are evidence for a cationmediated interaction between the $\mathrm{SO}_{4}{ }^{2-}$ and $\mathrm{COO}^{-}$anions. In order to better visualize the molecular picture described, a snapshot from a simulation of ( $\mathrm{Ile}+\mathrm{MgSO}_{4}+$ water) mixtures showing the relative positions of the ions around the amino acid is displayed in Figure 5, and the spatial distribution 
(a) ISOLEUCINE: Ct-anion ( $\mathrm{Cl}$ or $\mathrm{S})$

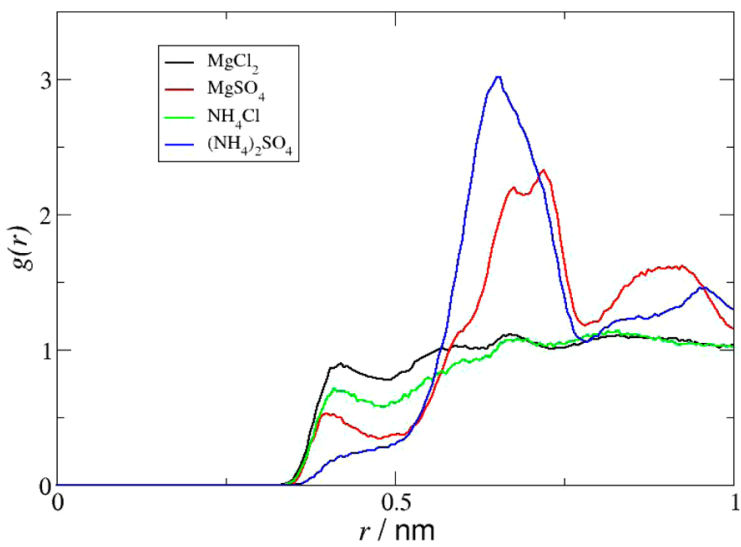

(b)

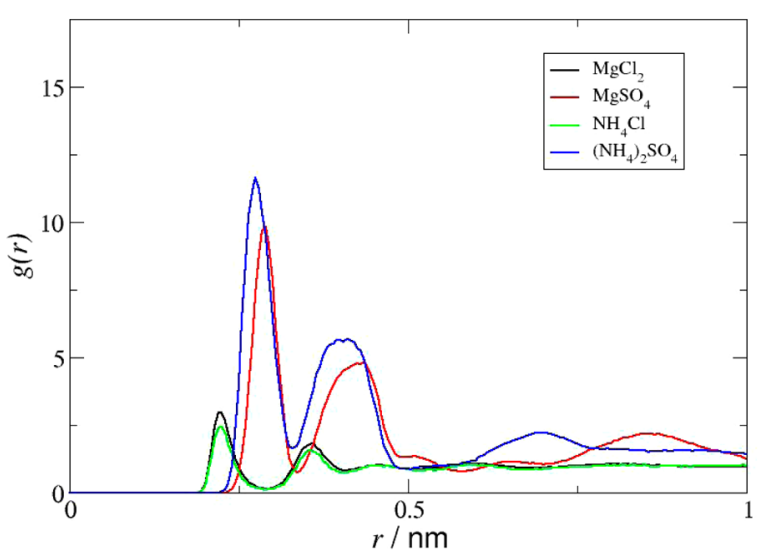

(c)

ISOLEUCINE: $\mathrm{O}_{\mathrm{COO}^{- \text {anion }}(\mathrm{Cl} \text { or } \mathrm{S})}$

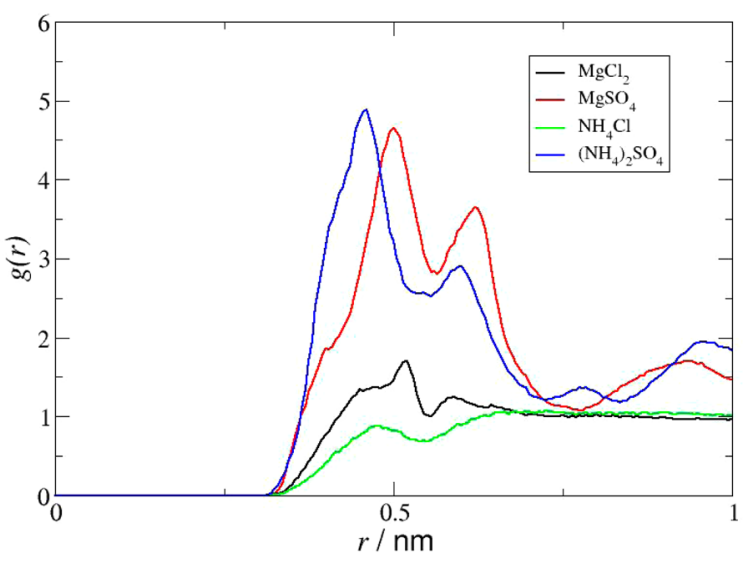

Figure 4. Radial distribution functions between different molecular regions of Ile and the central atom $(\mathrm{Cl}$ or $\mathrm{S})$ of the anion.

functions (SDF) calculated for this system are provided in Figure 6. As it can be seen in Figure 6a, the SDF region for the $\mathrm{Mg}^{2+}$ cation is between the region comprehended by the carboxyl group of Ile and the sulfate ion, supporting the idea of a $\mathrm{COO} \cdots \mathrm{Mg}^{2+} \ldots \mathrm{SO}_{4}{ }^{2-}$ configuration. Moreover, as shown in Figure $6 \mathrm{~b}$, the $\mathrm{SDF}$ regions for $\mathrm{SO}_{4}{ }^{2-}$ are mainly located at one of the sides of the amino acid, near the $\mathrm{NH}_{3}{ }^{+}$group, suggesting both a preferential presence of the anion near the positively

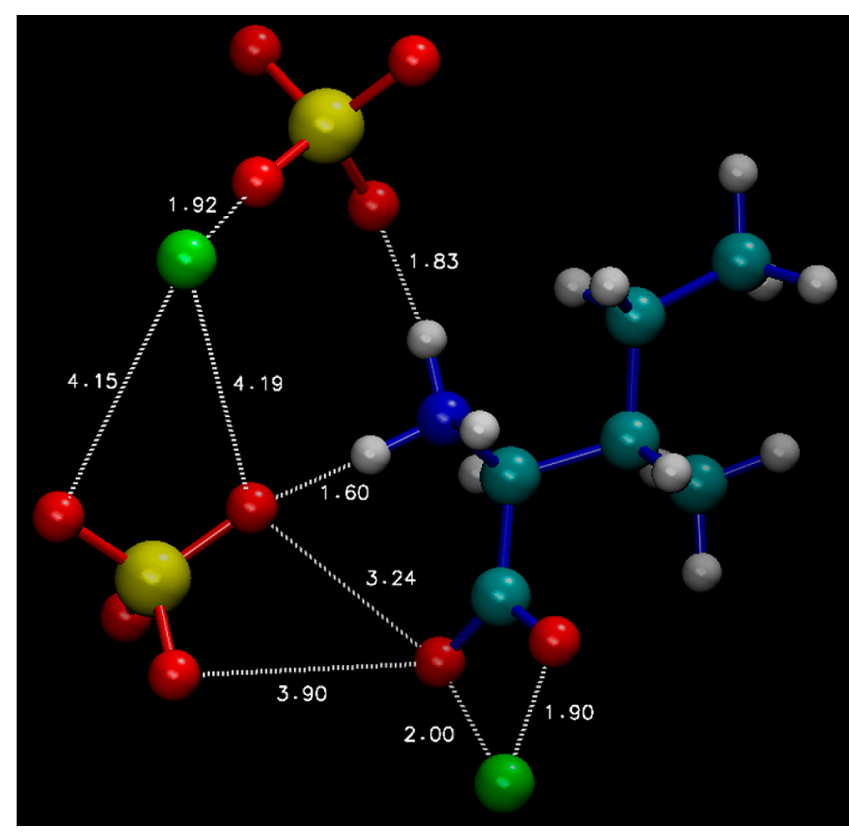

Figure 5. Snapshot from a simulation of (Ile $+\mathrm{MgSO}_{4}+$ water) mixtures, showing the distances $(\AA)$ between selected atoms. The water molecules are ommited for clarity. Light blue spheres represent carbon atoms, dark blue spheres are nitrogen atoms, red spheres are oxygens, white spheres are hydrogens, yellow spheres are sulfur, and green spheres are magnesium.

charged moiety of Ile and a less favorable presence in the vicinity of $\mathrm{COO}^{-}$.

As far as $\mathrm{Cl}^{-}$is concerned, the simulation results do not show any important association of the anion to the nonpolar moieties of the amino acids, but only interactions with the $\mathrm{NH}_{3}^{+}$group (albeit significantly weaker than for $\mathrm{SO}_{4}{ }^{2-}$ ). The patterns of the interactions described for Ile are also observed for Val (Figure S4, Supporting Information). In the case of Ala (Figure S3, Supporting Information), an apparent appreciable affinity for $\mathrm{C}_{t}$ is, however, a reflection of the interaction of the anions with the charged moieties of the amino acid due to the small size of the alkyl chain of the amino acid (all its carbon atoms are close to its charged moieties). These results support the salting-in/ salting-out mechanism based on the presence/absence of interactions between the low/high charge density anions and the hydrophobic moieties of the amino acids proposed before ${ }^{23}$ and are consistent with the lower impact of chloride salts observed experimentally and with the strong salting-out influence of the sulfate ion on the aqueous solubilities of amino acids. ${ }^{33,34,38}$ It has been shown ${ }^{43}$ that regardless of the cationic species used, $\mathrm{SO}_{4}{ }^{2-}$ salts promote salting-out effects of amino acids, proteins and other macromolecules, consistently with the behavior expected from the Hofmeister series of anions.

The Role of the Cation. Although the molecular interpretation of the influence of anions on the aqueous solubilities of biomolecules has generated much debate over the years, the molecular phenomena behind the cation-specific effects have been more difficult to explain and are still poorly understood. $^{42-45}$ To evaluate the role of the cation, we begin by considering the results obtained for $\mathrm{NH}_{4} \mathrm{Cl}$, a salt composed of weakly hydrated ions (Table 5). As shown in Figure 7a, $\mathrm{NH}_{4}{ }^{+}$is strongly associated to the carboxylate group of the amino acids, as suggested by the intense peaks corresponding 
(a)

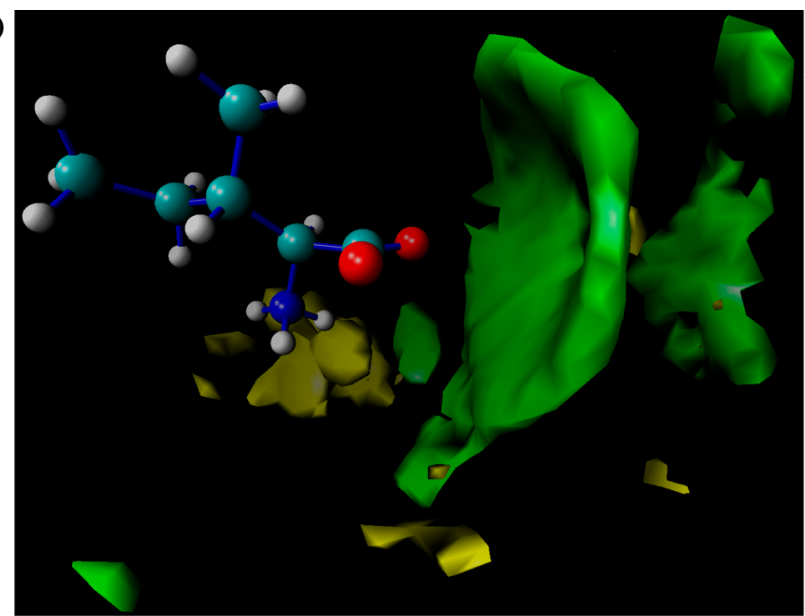

(b)

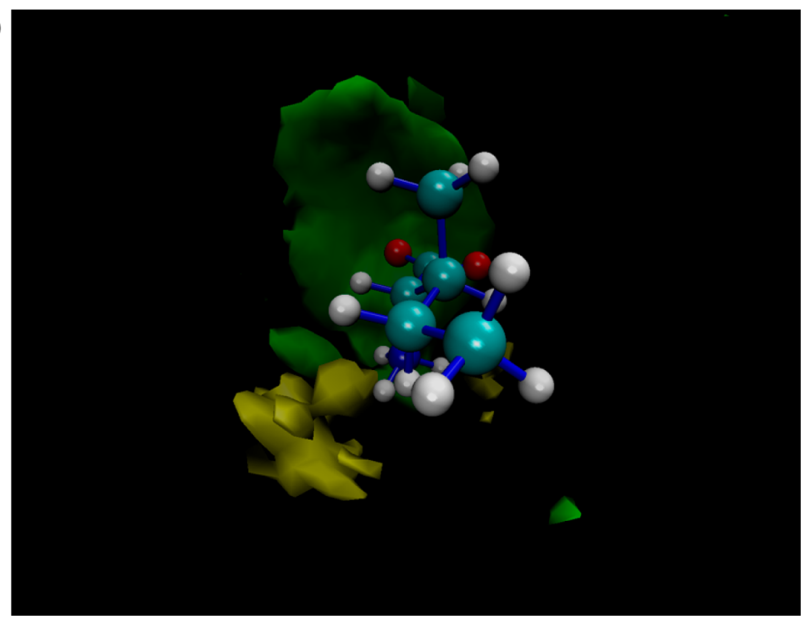

Figure 6. Spatial distribution functions (SDF) for the magnesium (green) and sulfate (yellow) ions around Ile in (Ile $+\mathrm{MgSO}_{4}+$ water) mixtures. Color code for the explicitly represented atoms is the same as in Figure 8.

to the contact pair $\mathrm{O}\left(\mathrm{COO}^{-}\right) \cdots \mathrm{N}\left(\mathrm{NH}_{4} \mathrm{Cl}\right)$. The $\mathrm{RDF}$ peaks displayed in Figure $7 \mathrm{~b}$ for the distribution of the $\mathrm{N}$ atom of $\mathrm{NH}_{4}^{+}$around $\mathrm{C}_{\mathrm{t}}$ of the amino acids indicate that the ammonium is present only at large distances. It seems thus that, contrarily to the salting-in anions, the weak binding of $\mathrm{NH}_{4}{ }^{+}$to the nonpolar moieties of the amino acids is not very significant, as observed in the case of sodium and potassium ions. ${ }^{23}$ To better support this result, the data obtained in this work for $\mathrm{NH}_{4} \mathrm{Cl}$ were compared to experimental ${ }^{34,38}$ and to simulation $^{23}$ data obtained previously for other salts comprising the same anion, $\mathrm{KCl}$ and $\mathrm{NaCl}$. As can be seen in Figure 8 for Ile and Figure S5 (Supporting Information) for Ala and Val, the simulation results do not reveal the presence of significant interactions of $\mathrm{NH}_{4}^{+}, \mathrm{K}^{+}$, and $\mathrm{Na}^{+}$with the hydrophobic groups of the amino acids, since the peaks observed in the RDFs of these cations around the $\mathrm{C}_{\mathrm{t}}$ atoms of Ala, Val, and Ile occur at large distances. The interactions of the ammonium ion are nevertheless somewhat stronger than those of $\mathrm{Na}^{+}$and $\mathrm{K}^{+}$, which are practically absent from the vicinity of the nonpolar parts of the biomolecules.

According to the MD results, the low charge density $\mathrm{NH}_{4}^{+}$ interacts weakly with the hydrophobic regions of $\mathrm{Ala}, \mathrm{Val}$ and Ile through a combination of ion-induced dipole and dispersion interactions, promoting a slender stabilization of the amino (a)

$\mathrm{O}\left(\mathrm{COO}^{-}\right.$, amino acid)_N $\left(\mathrm{NH}_{4} \mathrm{Cl}\right)$

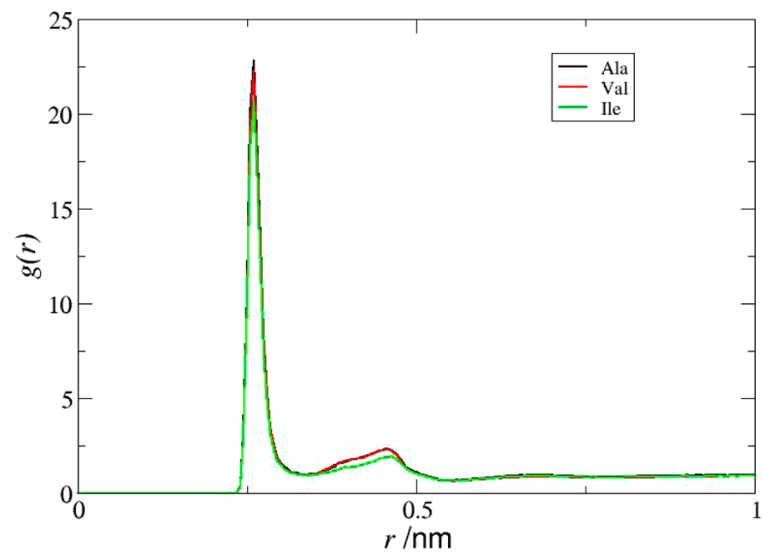

(b)

$\mathrm{C}_{\mathrm{t}}(\operatorname{amino}$ acid $) \_\mathrm{N}\left(\mathrm{NH}_{4} \mathrm{Cl}\right)$

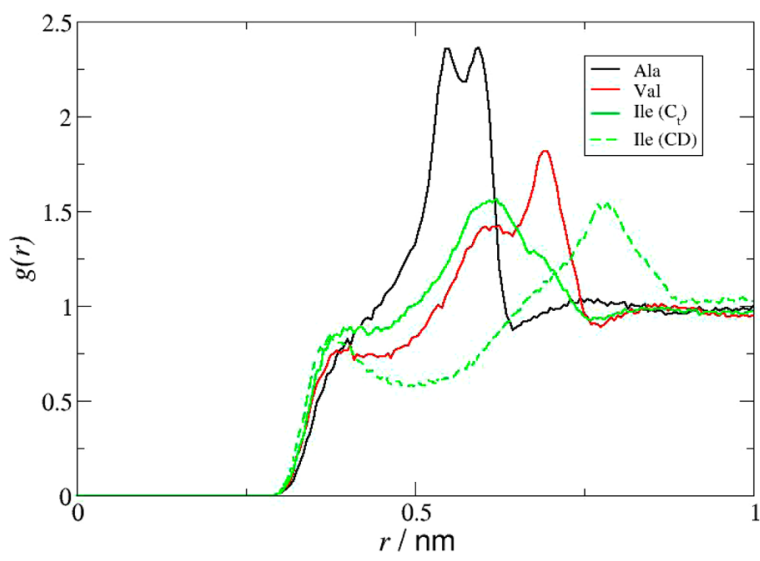

Figure 7. Radial distribution functions for the interactions between different molecular regions of the amino acids and the central atom (N) of the cation of $\mathrm{NH}_{4} \mathrm{Cl}$.

ISOLEUCINE: $\mathrm{C}_{\mathrm{t}-}$ cation

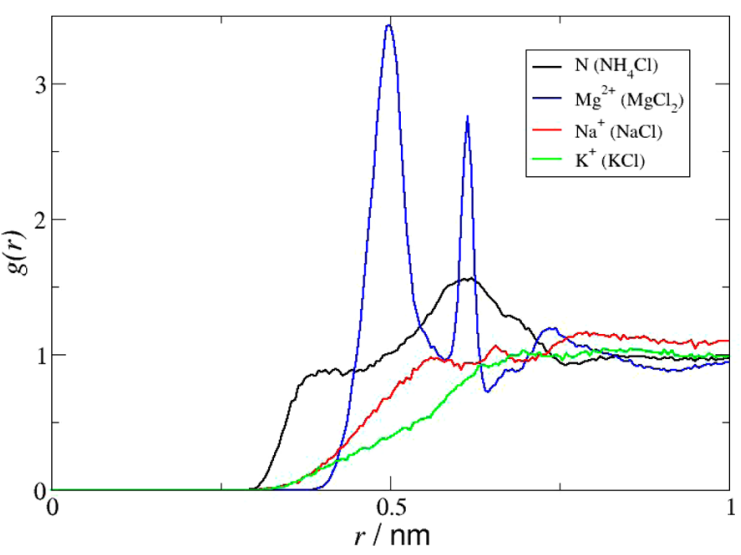

Figure 8. Radial distribution functions for the interactions between the cations of $\mathrm{NH}_{4} \mathrm{Cl}$ (this work), $\mathrm{MgCl}_{2}$ (this work), $\mathrm{NaCl}$ (ref 23), and $\mathrm{KCl}\left(\right.$ ref 23) and the terminal carbon atom $\left(\mathrm{C}_{\mathrm{t}}\right)$ of Ile.

acids in water and therefore a slight salting-in effect. On the other hand, almost no interactions occur in sodium and potassium aqueous solutions, and therefore even less pronounced impacts on the solubility are expected. These results are in good agreement with the experimental data 
available for the behavior of the systems under study, systematized in Figures S6 and S7 (Supporting Information). Indeed, as shown in Figure $\mathrm{S} 6$, while $\mathrm{NH}_{4} \mathrm{Cl}$ induces small increases in the solubility of $\mathrm{Ala}$ in water, $\mathrm{NaCl}$ promotes a slight salting-out effect. For $\mathrm{KCl}$, there are two contradictory experimental results, but the simulation data reported in this work does not support a salting-in influence of this salt. Instead, based on the observed absence of interactions between $\mathrm{K}^{+}$and the nonpolar groups of $\mathrm{Ala}$, a salting-out effect of $\mathrm{KCl}$ is expected, with a magnitude greater than that induced by $\mathrm{NaCl}$, as observed experimentally by some authors. ${ }^{38}$ Since the intensities of the RDF peaks referring to the $\mathrm{C}_{\mathrm{t}}$-cation contact pairs in Ile, Ala and Val mixtures (Figure 8 and Supporting Information Figure S5) decrease in the same order, the rank of the relative influence of the ions is likely to be similar among the systems considered. In fact, as presented in Figure S7 (Supporting Information), $\mathrm{NH}_{4} \mathrm{Cl}$ and $\mathrm{NaCl}$ induce, respectively, an increase and a slight decrease in the aqueous solubility of Val, while, inconsistently, the experimental data available for $\mathrm{KCl}$ is indicative of a salting-in effect. For Ile, the experimentally observed influence of $\mathrm{NH}_{4} \mathrm{Cl}$ (this work) is salting-in, but there is no solubility data available for the other two salts. It is worth to notice, however, that some differences observed in the RDFs of Figure 8 and Supporting Information Figure S5 when comparing the different amino acids might help to explain dissimilarities in the magnitude and/or direction of the effects promoted by the salts. This issue, related to the influence of the structural characteristics of the biomolecules, will be discussed below.

If, as previously shown ${ }^{23}$ and reinforced by the results reported above, there is no significant binding of $\mathrm{Cl}^{-}$with nonpolar regions, both in $\mathrm{KCl}$ and $\mathrm{NaCl}$ systems ${ }^{23}$ and in $\mathrm{NH}_{4} \mathrm{Cl}$ solutions, then the role of the cation-amino acid association will be dominant in determining the direction of the solubility effects induced by the salt. However, the evidence gathered for $\mathrm{NH}_{4} \mathrm{Cl}$ solutions suggests that the molecular mechanisms governing the cation-specific effects are different from those proposed for anions, according to which "chaotropic" species positioned in the extreme of the Hofmeister series, like $\mathrm{ClO}_{4}{ }^{-}$, establish favorable interactions with the nonpolar groups of the biomolecules, inducing, as a consequence, remarkable increases of their aqueous solubilities. $^{23}$

To acquire additional knowledge about the mechanism of action of the cations, we analyzed in detail the results obtained for the divalent magnesium ion. The RDFs depicted in Figure 8 and Supporting Information Figure S5 reveal the absence of direct interactions of $\mathrm{Mg}^{2+}$ with the nonpolar moieties of the amino acids, being the solvation layer occupied by water molecules as shown in Figure 3. On the other hand, the association of the cation to the charged groups, especially to the negatively charged carboxylate group, is exceptionally strong. Indeed, the RDF peaks corresponding to the contact pairs $\mathrm{Mg}^{2+} \ldots \mathrm{O}\left(\mathrm{COO}^{-}\right)$, displayed in Figure $9 \mathrm{~b}$ for Ile and in Figures S8 and S9 for Ala and Val (Supporting Information), are remarkably intense and occur at very short distances, indicating the presence of an extremely significant $\mathrm{Mg}^{2+}$ structuring around $\mathrm{COO}^{-}$. This suggests the formation of a complex of the cation with the amino acids, which would explain its strong salting-in influence. An issue that comes up in this context and which is worth noticing is that sometimes amino acid-salt RDFs cannot, per se, be directly related to the experimental solubility data. Actually, despite the presence of ion-amino acid short- (a)

ISOLEUCINE: Ct-cation ( $\mathrm{Mg}$ or $\mathrm{N}$ )

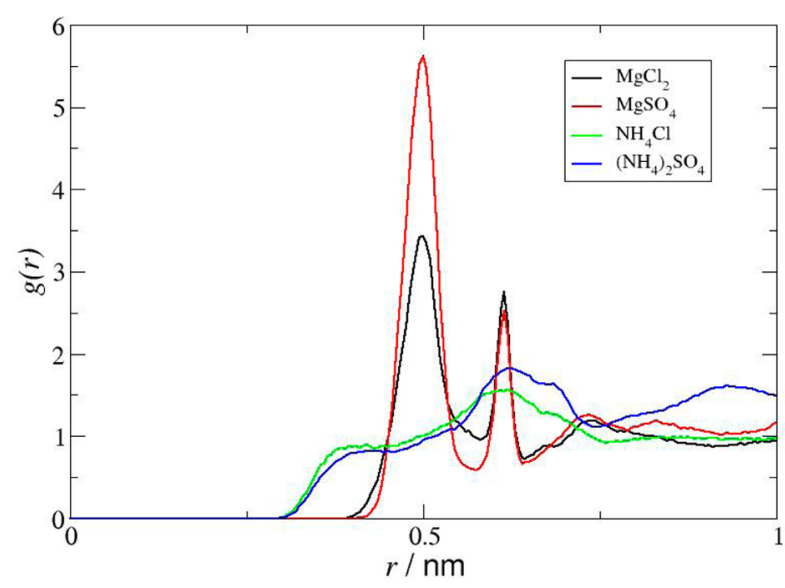

(b)

ISOLEUCINE: $\mathrm{O}_{\mathrm{COO}^{- \text {cation }}(\mathrm{Mg} \text { or } \mathrm{N})}$

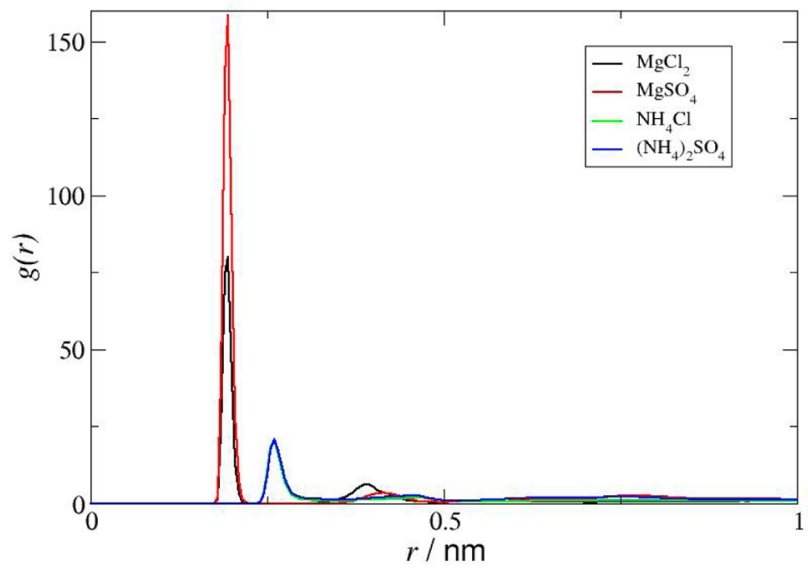

Figure 9. Radial distribution functions between different molecular regions of Ile and the central atom $(\mathrm{Mg}$ or $\mathrm{N})$ of the cation.

range correlations, the presence of the salt may cause enhanced amino acid-water correlations which can lead to salting-out (as opposed to salting-in which might be anticipated by analyzing the amino acid-salt RDF alone). For instance, it has been shown for aqueous sodium salt solutions of amides ${ }^{84}$ that, despite the observed short-range peak corresponding to the interaction of $\mathrm{Na}^{+}$with the carbonyl oxygen, this group is preferentially hydrated, resulting in salting-out by $\mathrm{NaCl}$ and not salting-in. Ion specific effects will not be therefore correctly interpreted unless the relative affinities of amino acid-salt and water-amino acid are compared. As it can be seen from the comparison of the relative intensities of the $\mathrm{RDF}$ peaks displayed in Figures $3 \mathrm{c}$ and $9 \mathrm{~b}$, not only the $\mathrm{Mg}^{2+}-\mathrm{O}\left(\mathrm{COO}^{-}\right)$ interaction is very strong, but also it is stronger than the $\mathrm{H}\left(\mathrm{H}_{2} \mathrm{O}\right)-\mathrm{O}\left(\mathrm{COO}^{-}\right)$association. This result provides support to the salting-in influence observed and explained for the magnesium salts.

A tridimensional picture of the interactions between the magnesium ion and the amino acids can be obtained from the spatial distribution functions (same isovalue as in Figure 6) calculated for the magnesium chloride salt around isoleucine, depicted in Figure 10. As shown in Figure 10a, the SDF regions for the $\mathrm{Mg}^{2+}$ ions are clearly located around the carboxyl group of the amino acid, as also observed in the case of $\mathrm{MgSO}_{4}$ mixtures (Figure 6). A few dissimilarities between the two 
(a)

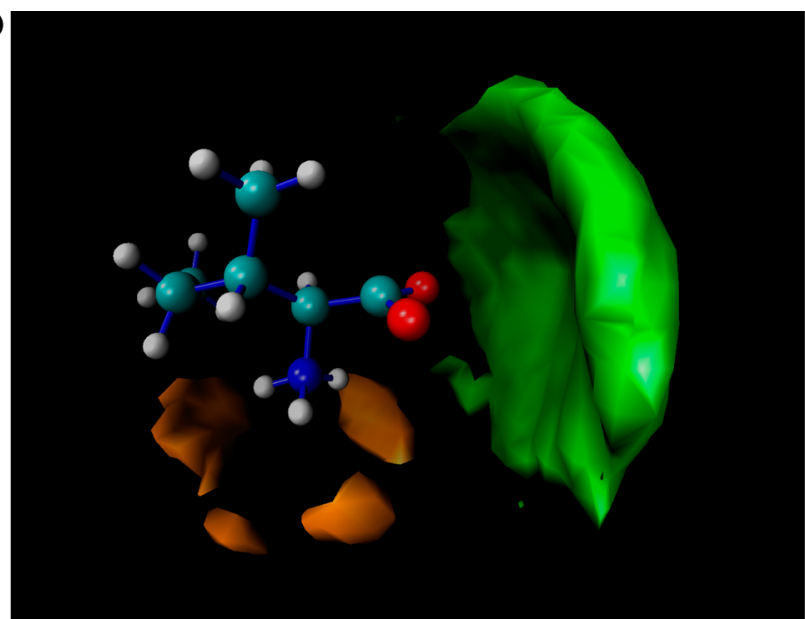

(b)

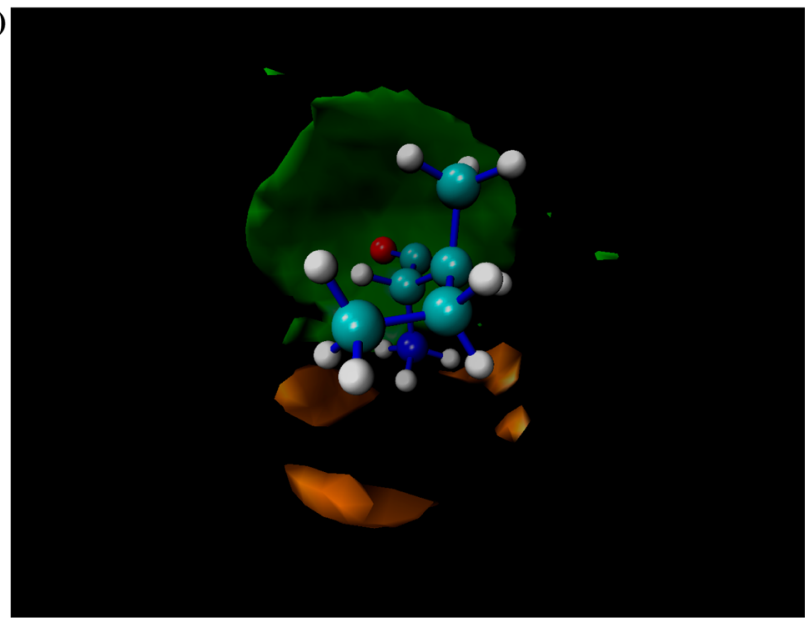

Figure 10. Spatial distribution functions (SDF) for the magnesium (green) and chloride (orange) ions around Ile in (Ile $+\mathrm{MgCl}_{2}+$ water) mixtures. Color code for the explicitly represented atoms is the same as in Figure 8.

magnesium salt systems considered are, however, worth noticing. First, the configuration of the type $\mathrm{COO}^{-} \cdots$ cation $\cdots$ anion observed in the case of the magnesium sulfate aqueous solutions (Figure 6) does not exist in the magnesium chloride mixtures (Figure 10a). Furthermore, while, as discussed above, the sulfate anion is preferentially positioned at one side of the amino acid, near the positively charged group of Ile and avoiding the vicinity of $\mathrm{COO}^{-}$(Figure $6 \mathrm{~b}$ ), $\mathrm{Cl}^{-}$, though also preferentially found close to $\mathrm{NH}_{3}{ }^{+}$, is located at both sides of the amino acid (Figure 10b).

Divalent cations have well recognized specific binding to proteins, negatively charged polyelectrolytes, peptides, nucleic acids, and fatty acid headgroups and are known to stabilize a variety of protein structures, ${ }^{44,45,85-88}$ but information on the exact nature of the interactions between those ions and the anionic groups of the biomolecules is vague and scarce. It is well-known that magnesium cations can form complexes with amino acids and proteins in aqueous solutions, ${ }^{89}$ and molecular models of those species have been proposed. ${ }^{78,86}$ Divalent magnesium ions seem to prefer ligands of low polarizability, with oxygen being the favorite coordinating atom, and have been found to bind directly to the polar hydrophilic protein residues, surrounded by a shell of nonpolar hydrophobic groups. In negatively charged structures, $\mathrm{Mg}^{2+}$ is directly bound to the negatively charged residues, and it has been suggested that the association is a stepwise process where some of its inner-shell water molecules are replaced by negatively charged side-chains. $^{86}$ Tian et al. $^{78}$ suggested a molecular structure for complexes between amino acids and magnesium ion. According to the authors, the cation is bound to four oxygen atoms, in a cyclic [amino acid-Mg-amino acid] complex. As discussed above (Figure 9), the simulation results obtained in this work suggest instead the possibility of the formation of a complex between the amino acids and $\mathrm{Mg}^{2+}$, which would be charged and consequently more soluble, justifying the pronounced salting-in effect induced by $\mathrm{MgCl}_{2}$. Since the intensity of the interactions between the carboxylate groups of the amino acids (Figure S10, Supporting Information) is decreased in the presence of $\mathrm{MgCl}_{2}$, our results do not support the presence of complexes of the type proposed by Tian et al. ${ }^{78}$ Though a clear description of the structure of amino acid-magnesium complexes cannot be found in literature and the data obtained in this work does not either allow to properly infer the molecular nature of those species, further support for the existence of such complexes can be provided by several studies. In fact, chelation of magnesium ions by carboxylic acids and amino acids in aqueous solutions has been considered before and the stability constants for such systems have been reported. $^{90-92}$ Moreover, the participation of the carboxyl group in the chelating reaction has been confirmed by spectroscopic methods. ${ }^{92}$ Other pharmaceutical and medical reports describe as well the use of preparations of magnesiumamino acid chelates as commercial products to treat human magnesium deficiency related diseases. ${ }^{93,94}$ Those chelate forms are very soluble and are known to be one of the most bioavailable forms of magnesium. ${ }^{94}$

Further evidence for the mechanism under study can be obtained from the analysis of the RDFs corresponding to the interactions between the $\mathrm{NH}_{4}^{+}, \mathrm{Mg}^{2+}, \mathrm{Na}^{+}$, and $\mathrm{K}^{+}$cations and the carboxylate group, displayed in Figure 11 for Ile and Figure S11 (Supporting Information) for Ala and Val. The comparison of the MD data reveals that the association of $\mathrm{Mg}^{2+}$ to $\mathrm{COO}^{-}$is indeed much more remarkable than that of the other cations, which can be understood in terms of the charge of these cations. The RDFs also suggest that the binding of $\mathrm{NH}_{4}{ }^{+}$to the carboxylate group is somewhat more important than that of

ISOLEUCINE: $\mathrm{O}\left(\mathrm{COO}^{-}\right)$_cation

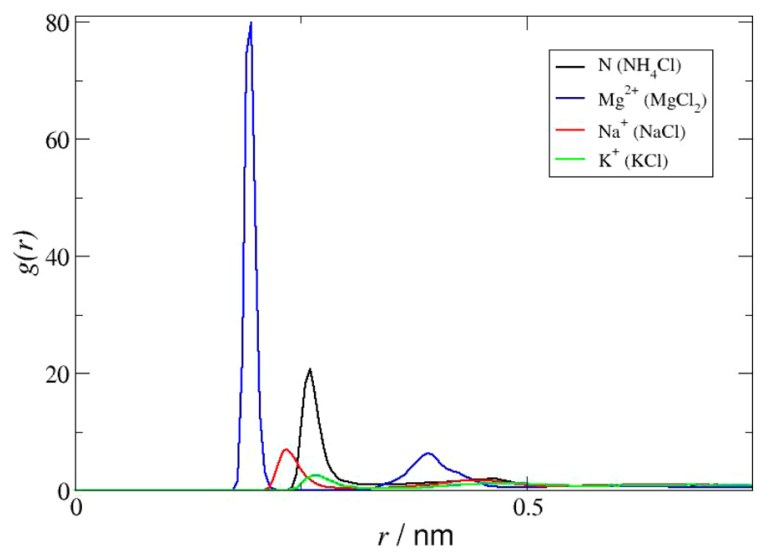

Figure 11. Radial distribution functions for the interactions between the cations of $\mathrm{NH}_{4} \mathrm{Cl}$ (this work), $\mathrm{MgCl}_{2}$ (this work), $\mathrm{NaCl}$ (ref 23), and $\mathrm{KCl}$ (ref 23) and the carboxyl group of isoleucine. 
$\mathrm{Na}^{+}$. Almost no interactions are observed for $\mathrm{K}^{+}$as indicated by the depletion of the peaks corresponding to the contact pair $\mathrm{K}^{+} \cdots \mathrm{O}\left(\mathrm{COO}^{-}\right)$. These observations are quantitatively corroborated by the values of the $\mathrm{CN}$ calculated for the interactions of the cations with the carboxyl group of the amino acids (Table 6) which decrease in the order $\mathrm{Mg}^{2+}>\mathrm{NH}_{4}^{+}>\mathrm{Na}^{+}>\mathrm{K}^{+}$.

Table 6. Calculated Coordination Numbers (CN) for the Interactions of the Cations with the Carboxyl Group of the Amino Acids in Salt/Water/Amino Acid Ternary Systems

\begin{tabular}{lccc}
\multicolumn{1}{c}{ interaction } & $\mathrm{Ala}$ & Val & Ile \\
$\mathrm{Mg}^{2+}\left(\mathrm{MgCl}_{2}\right)-\mathrm{O}\left(\mathrm{COO}^{-}\right)^{a}$ & 0.18 & 0.12 & 0.12 \\
$\mathrm{~N}\left(\mathrm{NH}_{4} \mathrm{Cl}\right)-\mathrm{O}\left(\mathrm{COO}^{-}\right)^{b}$ & 0.12 & 0.11 & 0.10 \\
$\mathrm{Na}^{+}(\mathrm{NaCl})-\mathrm{O}\left(\mathrm{COO}^{-}\right)^{c}$ & 0.03 & 0.05 & 0.03 \\
$\mathrm{~K}^{+}(\mathrm{KCl})-\mathrm{O}\left(\mathrm{COO}^{-}\right)^{d}$ & 0.02 & 0.01 & 0.02 \\
$\mathrm{Mg}^{2+}\left(\mathrm{MgSO}_{4}\right)-\mathrm{O}\left(\mathrm{COO}^{-}\right)^{e}$ & 0.12 & 0.12 & 0.24
\end{tabular}

${ }^{a}$ Calculated from the $\mathrm{Mg}^{2+}\left(\mathrm{MgCl}_{2}\right)-\mathrm{O}_{\mathrm{COO}}-\mathrm{RDF} .{ }^{b}$ Calculated from the $\mathrm{N}\left(\mathrm{NH}_{4} \mathrm{Cl}\right)-\mathrm{O}_{\mathrm{COO}^{-}} \mathrm{RDF}$. ${ }^{c}$ Calculated from the $\mathrm{Na}^{+}(\mathrm{NaCl})-$ $\mathrm{O}_{\mathrm{COO}^{-}}$RDF. ${ }^{d}$ Calculated from the $\mathrm{K}^{+}(\mathrm{KCl})-\mathrm{O}_{\mathrm{COO}^{-}} \mathrm{RDF} .{ }^{e}$ Calculated from the $\mathrm{Mg}^{2+}\left(\mathrm{MgSO}_{4}\right)-\mathrm{O}_{\mathrm{COO}}-\mathrm{RDF}$.

These results suggest that because of its high charge density, $\mathrm{Mg}^{2+}$ is able to form charged complexes with the amino acids, which are very soluble and will have a positive effect on the strong salting-in influence of this ion. The association of $\mathrm{NH}_{4}^{+}$ to the carboxylate group is much less intense than that involving the $\mathrm{Mg}^{2+}$ cation. Nevertheless this interaction may anticipate the formation of weak single charged positive complexes which are less soluble than the double charged ones formed in the case of aqueous solutions containing magnesium salts. Therefore less pronounced salting-in effects are promoted by $\mathrm{NH}_{4} \mathrm{Cl}$ as observed experimentally in this work (Tables 1 and 3, Figure $2 \mathrm{a}$ ). $\mathrm{Na}^{+}$and particularly $\mathrm{K}^{+}$are not able to establish such interactions, probably because their solvation by the water molecules is more favorable (Table 5), and their solubility effects are then governed by a distinct mechanism as discussed above. Previous works on this subject provide further support to this interpretation. In fact, it has been argued that ammonium and sodium ions cannot form cyclo-complexes with amino acids in the same way as magnesium and other divalent cations such as $\mathrm{Ca}^{2+},{ }^{78} \mathrm{Na}^{+}$, and $\mathrm{K}^{+}$are often viewed as roughly neutral. ${ }^{95}$ Density functional theory calculations of the relative stability of gasphase complexes between metal ions and amino acids ${ }^{96-98}$ have shown that the Gibbs energies of (ion-amino acid) systems are much less positive in the case of divalent ions than of monovalent ions. For instance, for (ion-arginine) complexes, ${ }^{96}$ the values of the gas-phase Gibbs energies follow the order $\mathrm{Ni}^{2+}$ $\left(-1544 \mathrm{~kJ} \mathrm{~mol}^{-1}\right)<\mathrm{Cu}^{2+}\left(-1404 \mathrm{~kJ} \mathrm{~mol}^{-1}\right)<\mathrm{Zn}^{2+}(-1280 \mathrm{~kJ}$ $\left.\mathrm{mol}^{-1}\right)<\mathrm{Mg}^{2+}\left(-1028 \mathrm{~kJ} \mathrm{~mol}^{-1}\right)<\mathrm{Ca}^{2+}\left(-660 \mathrm{~kJ} \mathrm{~mol}^{-1}\right)<\mathrm{Li}$ $+\left(-328 \mathrm{~kJ} \mathrm{~mol}^{-1}\right)<\mathrm{Na}^{+}\left(-225 \mathrm{~kJ} \mathrm{~mol}^{-1}\right)<\mathrm{K}^{+}(-152 \mathrm{~kJ}$ $\left.\mathrm{mol}^{-1}\right)$, at $T=298.15 \mathrm{~K}$.

All evidence suggests that the mechanism by which salting-in inducing cations act in aqueous solutions of amino acids is different from that of anions. Contrarily to these, salting-in cations do not establish important interactions with the nonpolar moieties of the biomolecules, but instead with their charged parts, especially with the carboxylate group. The type and strength of that association will determine the differences found in the magnitude of the solubility effects promoted. Divalent cations such as $\mathrm{Mg}^{2+}$ are able to form charged and very soluble complexes with the amino acids, therefore acting as strong salting-in agents. For monovalent cations like $\mathrm{NH}_{4}{ }^{+}$, the binding to $\mathrm{COO}^{-}$still occurs but is less favorable, and therefore, the ammonium ion promotes only a slight increase in the aqueous solubilities of the amino acids. When the solvation by water of some cations is more favorable than the interaction with the carboxylate, it leads to a decrease in the aqueous solubility of the biomolecules and the underlying molecular mechanism is thus similar to that observed for the salting-out effects of anions. Interestingly, this reversal in the Hofmeister series for cations is observed in systems containing sites of negative charge ${ }^{45,80}$ but not in systems comprising neutral biocompounds or other types of molecules. ${ }^{57,79}$ For instance, in IL-based aqueous two-phase systems, the magnesium behaves as a salting-out inducing ion ${ }^{79}$ since it is readily solvated by water and thus does not interact with the low charge density IL anion.

The Cation-Anion Competition. While the data obtained in this work for the chloride salts, comprising different cations with a weakly hydrated anion, enables the clarification of the mechanism by which salting-in inducing cations operate in aqueous solutions of amino acids, the analysis of the results for the sulfate salts, containing a strongly hydrated anion, allows the elucidation of the competing effects of the cation and anion on these systems.

A brief comparison of the experimental and simulation data obtained for $\mathrm{NH}_{4} \mathrm{Cl}$ versus $\left(\mathrm{NH}_{4}\right)_{2} \mathrm{SO}_{4}$ or $\mathrm{MgCl}_{2}$ versus $\mathrm{MgSO}_{4}$ aqueous solutions of $\mathrm{Val}$ provides further insight into the molecular interaction mechanism proposed here. According to the results obtained in this work (Tables 1-4, Figure 2) the presence of a salting-out anion leads to a decrease of the magnitude of the salting-in induced by the cation and, in the case of $\left(\mathrm{NH}_{4}\right)_{2} \mathrm{SO}_{4}$, even to a change in direction of the solubility effect. It is therefore reasonable to conjecture that when the anion is sulfate, the interactions of the cations with the amino acids are overcome by the interactions occurring between the anion and the other species of the system.

As shown in Figure S4 (Supporting Information) and Figure 12 for $\mathrm{Val}, \mathrm{SO}_{4}^{2-}$ is significantly associated to the charged groups of the amino acid, but shows no binding to its nonpolar moieties and has a very favorable hydration. Its action is thus ruled by the mechanism previously proposed for the salting-out anions. ${ }^{23}$ In systems containing cations such as $\mathrm{NH}_{4}{ }^{+}$, with a relatively small affinity to the amino acid, the sulfate ion, behaving as a strong salting-out inducing ion, controls the solubility effect promoted by the salt. As reported in this work (Table 2 and Figure 2), a decrease in the aqueous solubility of Val in the presence of ammonium sulfate is observed. On the other hand, when $\mathrm{SO}_{4}{ }^{2-}$ is the counterion of $\mathrm{Mg}^{2+}$, a cation that strongly associates to the amino acid, a complex interplay of interactions will take place and their balance will determine the final effect observed. The less pronounced increases in the solubility of Val in aqueous solutions of magnesium sulfate relatively to the magnesium chloride systems can therefore be explained in terms of a competition between the interactions established, in which the salting-out formation of hydration complexes by $\mathrm{SO}_{4}{ }^{2-}$ is balanced by the salting-in effect of the strong $\mathrm{Mg}^{2+} / \mathrm{COO}^{-}$interactions.

The conclusions derived from the analysis of the results obtained for the aqueous solutions of Val gain further support when Ala and Ile solutions are considered. In fact, similar interaction patterns are observed for these amino acids (Figures S3 and S4, Supporting Information), enabling one to interpret the more pronounced increase of the solubility of these amino 
$\mathrm{VALINE}+\mathrm{MgSO}_{4}+$ water

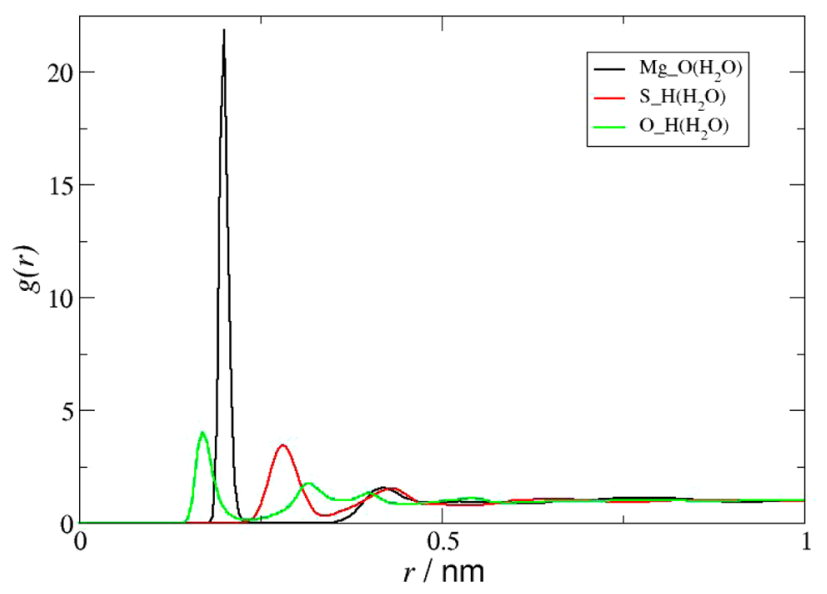

VALINE + $\left(\mathrm{NH}_{4}\right)_{2} \mathrm{SO}_{4}+$ water

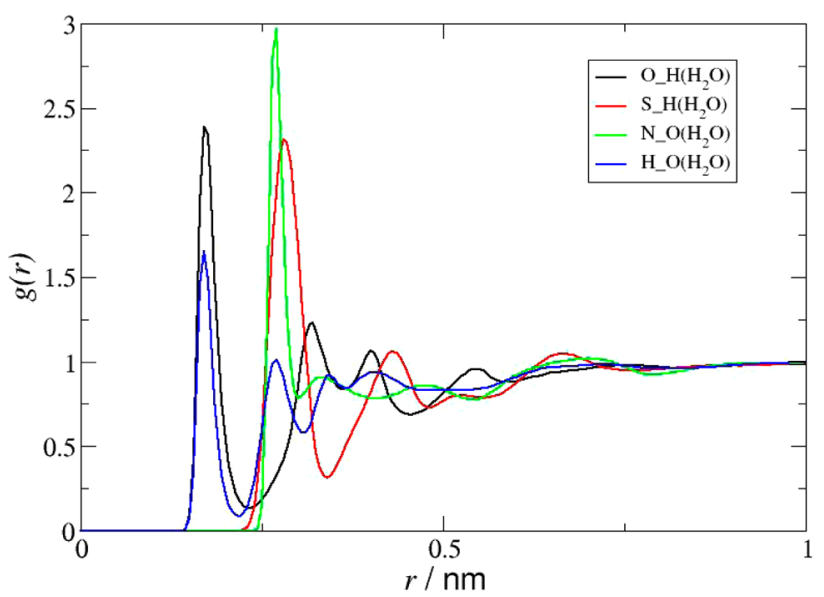

Figure 12. Radial distribution functions for the interactions between water molecules and the ions in aqueous solutions of $\mathrm{Val}$ in the presence of $\mathrm{MgSO}_{4}$ and $\left(\mathrm{NH}_{4}\right)_{2} \mathrm{SO}_{4}$.

acids in the presence of $\mathrm{MgCl}_{2}$ than in mixtures containing $\mathrm{MgSO}_{4}$ (Tables 3 and 4, Figure $2 \mathrm{~b}$ ), and the salting-out of Ile occurring in concentrated solutions of $\left(\mathrm{NH}_{4}\right)_{2} \mathrm{SO}_{4}{ }^{40}$

In summary, when the salts comprise an anion with low hydration energy, the direction and magnitude of the solubility influence observed will be almost only governed by the nature of the cation. When the anion has a significantly favorable hydration, both the cation and the anion will have a role on the solubility impact of the salt, and a complex balance of competitive interactions will determine its influence.

\section{CONCLUSIONS}

Experimental solubility measurements and MD simulations were performed to obtain further insight into the molecularlevel interactions that control the solubility behavior of amino acids in aqueous saline environments. The results obtained enable to clarify the role of the cation and of the anion on the mechanisms by which salts operate in aqueous solutions of amino acids. The evidence gathered shows that the molecular phenomena governing the action of salting-in inducing cations is different from those behind the effects of anions. Contrary to the latter, salting-in inducing cations do not establish important interactions with the nonpolar moieties of the biomolecules, but instead with their charged parts, especially with the carboxylate group. The type and strength of that association is determined by the charge properties of the cation and will be responsible for the differences found in the magnitude of the solubility increases promoted. When the anion has a favorable hydration, both the cation and the anion will have a predominant role on the solubility impact of the salt, and a complex balance of competitive interactions will rule its influence.

Since amino acids can be taken as model systems, the molecular-level mechanism reported here can be helpful for understanding the solubility and stability behavior of other more complex biomolecules in aqueous electrolyte solutions, and thus be relevant to develop many areas of biotechnology and life sciences.

\section{ASSOCIATED CONTENT}

\section{Supporting Information}

Additonal figures as described in the text. This material is available free of charge via the Internet at http://pubs.acs.org.

\section{AUTHOR INFORMATION}

\section{Corresponding Author}

*Corresponding author Tel: +351-234-370200; Fax: +351-234370084; E-mail address: jcoutinho@ua.pt.

\section{Notes}

The authors declare no competing financial interest.

\section{ACKNOWLEDGMENTS}

The authors thank financial support from Fundação para a Ciência e a Tecnologia for Programa Ciência 2007 and the postdoctoral grant SFRH/BPD/44926/2008 awarded to L.I.N.T. This work is partially supported by projects PEst-C/ EQB/LA0020/2011 and PEst-C/CTM/LA0011/2011, financed by FEDER through COMPETE - Programa Operacional Factores de Competitividade and by FCT - Fundação para a Ciência e a Tecnologia.

\section{REFERENCES}

(1) Mader, S. Biology, 9th ed.; McGraw Hill: New York, 2007.

(2) Chiti, F.; Dobson, C. M. Annu. Rev. Biochem. 2006, 75, 333.

(3) Dennis, J. S. Nature 2003, 426, 900.

(4) Zhao, H. J. Mol. Catal. B: Enzym. 2005, 37, 16.

(5) Eyal, A. M.; Bressler, E. Biotechnol. Bioeng. 1993, 41, 287.

(6) Hofmeister, F. Arch. Exp. Pathol. Pharmakol. 1888, XXIV, 247.

(7) Kunz, W.; Henle, J.; Ninham, B. W. Curr. Opin. Colloid Interface Sci. 2004, 9, 19.

(8) Collins, K. D.; Washabaugh, M. W. Q. Rev. Biophys. 1985, 18, 323.

(9) Zhang, Y. J.; Furyk, S.; Bergbreiter, D. E.; Cremer, P. S. J. Am. Chem. Soc. 2005, 127, 14505.

(10) Bauduin, P.; Nohmie, F.; Touraud, D.; Neueder, R.; Kunz, W.; Ninham, B. W. J. Mol. Liq. 2006, 123, 14.

(11) Batchelor, J. D.; Olteanu, A.; Tripathy, A.; Pielak, G. J. J. Am. Chem. Soc. 2004, 126, 1958.

(12) Vanzi, F.; Madan, B.; Sharp, K. J. Am. Chem. Soc. 1998, 120, 10748.

(13) Washabaugh, M. W. Q.; Collins, K. D. J. Biol. Chem. 1986, 261, 2477.

(14) Zou, Q.; Bennion, B. J.; Daggett, V.; Murphy, K. P. J. Am. Chem. Soc. 2002, 124, 1192.

(15) Bostrom, M.; Williams, D. R. M.; Ninham, B. W. Biophys. J. 2003, 85, 686.

(16) Bostrom, M.; Williams, D. R. M.; Ninham, B. W. Phys. Rev. Lett. 2001, 87, 168103. 
(17) Zhang, Y. J.; Furyk, S.; Sagle, L. B.; Cho, Y.; Bergbreiter, D. E.; Cremer, P. S. J. Phys. Chem. C 2007, 111, 8916.

(18) Zhang, Y. J.; Cremer, P. S. Curr. Opin. Colloid Interface Sci. 2006, 10, 658 .

(19) Tomé, L. I. N.; Varanda, F. R.; Freire, M. G.; Marrucho, I. M.; Coutinho, J. A. P. J. Phys. Chem. B 2009, 113, 2815.

(20) Tomé, L. I. N.; Domínguez-Pérez, M.; Cláudio, A. F. M.; Freire, M. G.; Marrucho, I. M.; Cabeza, O.; Coutinho, J. A. P. J. Phys. Chem. B 2009, 113, 13971.

(21) Freire, M. G.; Carvalho, P. J.; Silva, A. M. S.; Santos, L. M. N. B. F.; Rebelo, L. P. N.; Marrucho, I. M.; Coutinho, J. A. P. J. Phys. Chem. B 2009, 113, 202

(22) Freire, M. G.; Neves, C. M. S. S.; Silva, A. M. S.; Santos, L. M. N. B. F.; Marrucho, I. M.; Rebelo, L. P. N.; Shah, J. K.; Maggin, E. J.; Coutinho, J. A. P. J. Phys. Chem. B 2010, 114, 2004.

(23) Tomé, L. I. N.; Jorge, M.; Gomes, J. R. B.; Coutinho, J. A. P. J. Phys. Chem. B 2010, 114, 16450.

(24) Tomé, L. I. N.; Jorge, M.; Gomes, J. R. B.; Coutinho, J. A. P. J. Phys. Chem. B 2012, 116, 1831.

(25) Holz, M.; Grunder, R.; Sacco, A.; Meleleo, A. J. Chem. Soc., Faraday Trans. 1993, 89, 1215.

(26) Holz, M. J. Mol. Liq. 1995, 67, 175.

(27) Sacco, A.; De Cillis, F. M.; Holz, M. J. Chem. Soc., Faraday Trans. 1998, 94, 2089.

(28) Westh, P.; Kato, H.; Nitshikawa, K.; Koga, Y. J. Phys. Chem. A 2006, 110, 2072.

(29) Kalra, A.; Tugcu, N.; Cramer, S. M.; Garde, S. J. Phys. Chem. B 2001, 105, 6380.

(30) Zangi, R.; Hagen, M.; Berne, B. J. J. Am. Chem. Soc. 2007, 129, 4678

(31) Parsons, D. F.; Bostrom, M.; Lo Nostro, P.; Ninham, B. W. Phys. Chem. Chem. Phys. 2011, 13, 12352.

(32) Klahn, M.; Lim, G. S.; Seduraman, A.; Wu, P. Phys. Chem. Chem. Phys. 2011, 13, 1649.

(33) Carta, R.; Tola, G. J. Chem. Eng. Data 1996, 41, 414.

(34) Khoshkbarchi, M. K.; Vera, J. H. Ind. Eng. Chem. Res. 1997, 36, 2445

(35) Carta, R. J. Chem. Thermodyn. 1998, 30, 379.

(36) Pradhan, A. A.; Vera, J. H. J. Chem. Eng. Data 2000, 45, 140.

(37) Ramasami, P. J. Chem. Eng. Data 2002, 47, 1164.

(38) Ferreira, L. A.; Macedo, E. A.; Pinho, S. P. Ind. Eng. Chem. Res. 2005, 44, 8892.

(39) Ferreira, L. A.; Macedo, E. A.; Pinho, S. P. Fluid Phase Equilib. 2007, 255, 131.

(40) Ferreira, L. A.; Macedo, E. A.; Pinho, S. P. J. Chem. Thermodyn. 2009, 41, 193.

(41) Brown, M. G.; Rousseau, R. W. Biotechnol. Prog. 1994, 10, 253.

(42) El-Dossoki, F. I. J. Solution Chem. 2010, 39, 1311.

(43) Arakawa, T.; Timasheff, S. N. Biochemistry 1984, 23, 5912.

(44) Sabbagh, I.; Delsanti, M. Eur. Phys. J. E 2000, 1, 75-86.

(45) Kherb, J.; Flores, S. C.; Cremer, P. S. J. Phys. Chem. B 2012, 116, $7389-7397$.

(46) Heyda, J.; Vincent, J. C.; Tobias, D. J.; Dzubiella, J.; Jungwirth, P. J. Phys. Chem. B 2010, 114, 1213.

(47) Lund, M.; Vrbka, L.; Jungwirth, P. J. Am. Chem. Soc. 2008, 130, 11582 .

(48) Vrbka, L.; Jungwirth, P.; Bauduin, P.; Touraud, D.; Kunz, W. J. Phys. Chem. B 2006, 110, 7036.

(49) Heyda, J.; Hrobárik, T.; Jungwirth, P. J. Phys. Chem. A 2009, 113, 1969.

(50) Sagarik, K.; Dokmaisrijan, S. J. Mol. Struct.: THEOCHEM 2005, $718,31$.

(51) Fujita, T.; Watanabe, H.; Tanaka, S. Chem. Phys. Lett. 2007, 434, 42.

(52) Hess, B.; van der Vegt, N. Proc. Natl. Acad. Sci. U.S.A. 2009, 106, 13296.

(53) Vrbka, L.; Vondrásek, J.; Jagoda-Cwiklik, B.; Vácha, R.; Jungwirth, P. Proc. Natl. Acad. Sci. U.S.A. 2006, 103, 15440.
(54) Fedorov, M. V.; Goodman, J. M.; Schumm, S. J. Am. Chem. Soc. 2009, 131, 10854.

(55) Cordomi, A.; Edholm, O.; Perez, J. J. J. Phys. Chem. B 2008, 112, 1397.

(56) Heyda, J.; Lund, M.; Oncák, M.; Slavícek, P.; Jungwirth, P. J. Phys. Chem. B 2010, 114, 10843.

(57) Basak, B.; Bhattacharyya, U. K.; Sinhababu, A.; Laskar, S. Appl. Biochem. Biotechnol. 1994, 49, 281.

(58) Breil, M. P.; Mollerup, J. M.; Rudolph, E. S. J.; Ottens, M.; van der Wielen, L. A. M. Fluid Phase Equilib. 2004, 215, 221.

(59) Hess, B.; Kutzner, C.; van der Spoel, D.; Lindahl, E. J. Chem. Theory Comput. 2008, 4, 435.

(60) Hockney, R. W.; Goel, S. P. J. J. Comput. Phys. 1974, 14, 148.

(61) Nosé, S. Mol. Phys. 1984, 52, 255.

(62) Hoover, W. G. Phys. Rev. A 1985, 31, 1695.

(63) Parrinello, M.; Rahman, A. J. Appl. Phys. 1981, 52, 7182.

(64) Essman, U.; Perela, L.; Berkowitz, M. L.; Darden, T.; Lee, H.; Pederson, L. G. J. Chem. Phys. 1995, 103, 8577.

(65) Hess, B.; Bekker, H.; Berendsen, H. J. C.; Fraaije, J. G. E. M. J. Comput. Chem. 1997, 18, 1463.

(66) Berendsen, H. J. C.; Grigera, J. R.; Straatsma, T. P. J. Phys. Chem. 1997, 91, 6269

(67) Aqvist, J. J. Phys. Chem. 1990, 94, 8021.

(68) Chandrasekhar, J.; Spellmeyer, D. C.; Jorgensen, W. L. J. Am. Chem. Soc. 1984, 106, 903.

(69) Jorgensen, W. L.; Gao, J. J. Phys. Chem. 1986, 90, 2174.

(70) Cannon, W. R.; Pettitt, B. M.; McCammon, J. A. J. Phys. Chem. 1994, 98, 6225

(71) Weerasinghe, S.; Smith, P. E. J. Chem. Phys. 2003, 119, 11342. (72) Hess, B.; Holm, C.; van der Vegt, N. J. Chem. Phys. 2006, 124, 164509.

(73) Yoo, J.; Aksimentiev, A. J. Phys. Chem. Lett. 2012, 3, 45.

(74) Fyta, M.; Kalcher, I.; Dzubiella, J.; Vrbka, L.; Netz, R. R. J. Chem. Phys. 2010, 132, 24911.

(75) Joung, I. S.; Cheatham, T. E., III. J. Phys. Chem. B 2009, 113, 13279.

(76) Marcus, Y. Ion Properties; Marcus Dekker, Inc.: New York, 1997. (77) Marcus, Y. J. Chem. Soc., Faraday Trans. 1991, 87, 2995.

(78) Tian, J.; Yin, Y.; Sun, H.; Luo, X. J. Magn. Reson. 2002, 159, 137.

(79) Shahriari, S.; Neves, C. M. S. S.; Freire, M. G.; Coutinho, J. A. P. J. Phys. Chem. B 2012, 116, 7252-7258.

(80) Fuser, G.; Steinbuchel, A. Biomacromolecules 2005, 6, 1367.

(81) Hutchens, J. O. Handbook of Biochemistry and Molecular Biology: Physical and Chemical Data, 3rd ed.; CRC Press: Cleveland, 1976; Vol.

(82) Kurosawa, I. Solid-Liquid Equilibrium in Multi Solute Systems, 2004.

(83) Matsuo, H.; Suzuki, Y.; Sawamura, S. Fluid Phase Equilib. 2002, 200, 227.

(84) Algaer, E. A.; van der Vegt, N. F. A. J. Phys. Chem. B 2011, 115, 13781.

(85) Darnell, J.; Lodish, H.; Baltimore, D. Molecular Cell Biology; Scientific American Books: New York, 1990.

(86) Dudev, T.; Lim, C. Chem. Rev. 2003, 103, 773-787.

(87) Bulo, R. E.; Donadio, D.; Laio, A.; Molnar, F.; Rieger, J. Macromolecules 2007, 40, 3437-3442.

(88) Gurau, M. C.; Kim, G.; Lim, S. M.; Albertorio, F.; Fleisher, H. C.; Cremer, P. S. Chem. Phys. Chem. 2003, 4, 1231-1233.

(89) Greenstein, J. P.; Wintz, M. Chemistry of the amino acids; John Wiley \& Sons Inc.: New York, 1961; Vol. 1.

(90) Panuyshkin, V. T.; Sukhno, I. V.; Arutunyan, M. M. J. Mol. Liq. 2001, 92, 235.

(91) Gorton, J. E.; Jameson, R. F. J. Chem. Soc., Dalton Trans. 1972, 3, 310.

(92) Okabayashi, Y.; Hayashi, F.; Terui, Y.; Kitagawa, T. Chem. Pharm. Bull. 1992, 40, 692.

(93) Geiger, H.; Wanner, C. Clin. Kidney J. 2012, 5, i-25.

(94) Walker, A. F.; Marakis, G.; Christie, S.; Byng, M. Magnes. Res. 2003, 16, 183. 
(95) Collins, K. D. Biophys. J. 1997, 72, 65-76.

(96) Remko, M.; Fitz, D.; Rode, B. M. J. Phys. Chem. A 2008, 112, 7652.

(97) Remko, M.; Fitz, D.; Rode, B. M. Amino Acids 2010, 39, 1309.

(98) Remko, M.; Rode, B. M. J. Phys. Chem. A 2006, 110, 1960. 